NASA Technical Memorandum 4465

$$
2.26
$$

\title{
Summary of the Effects of Engine Throttle Response on Airplane Formation-Flying Qualities
}

Kevin R. Walsh

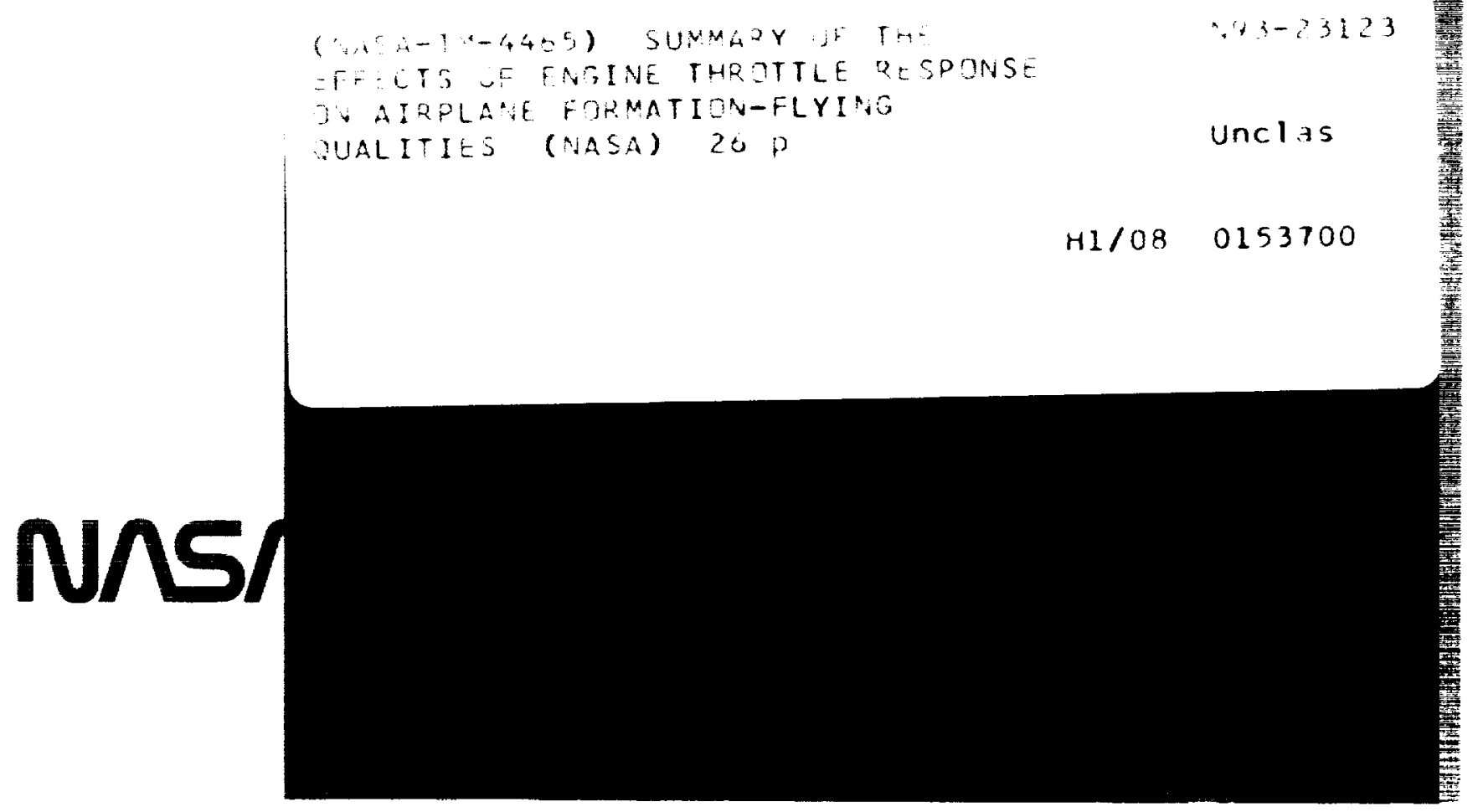




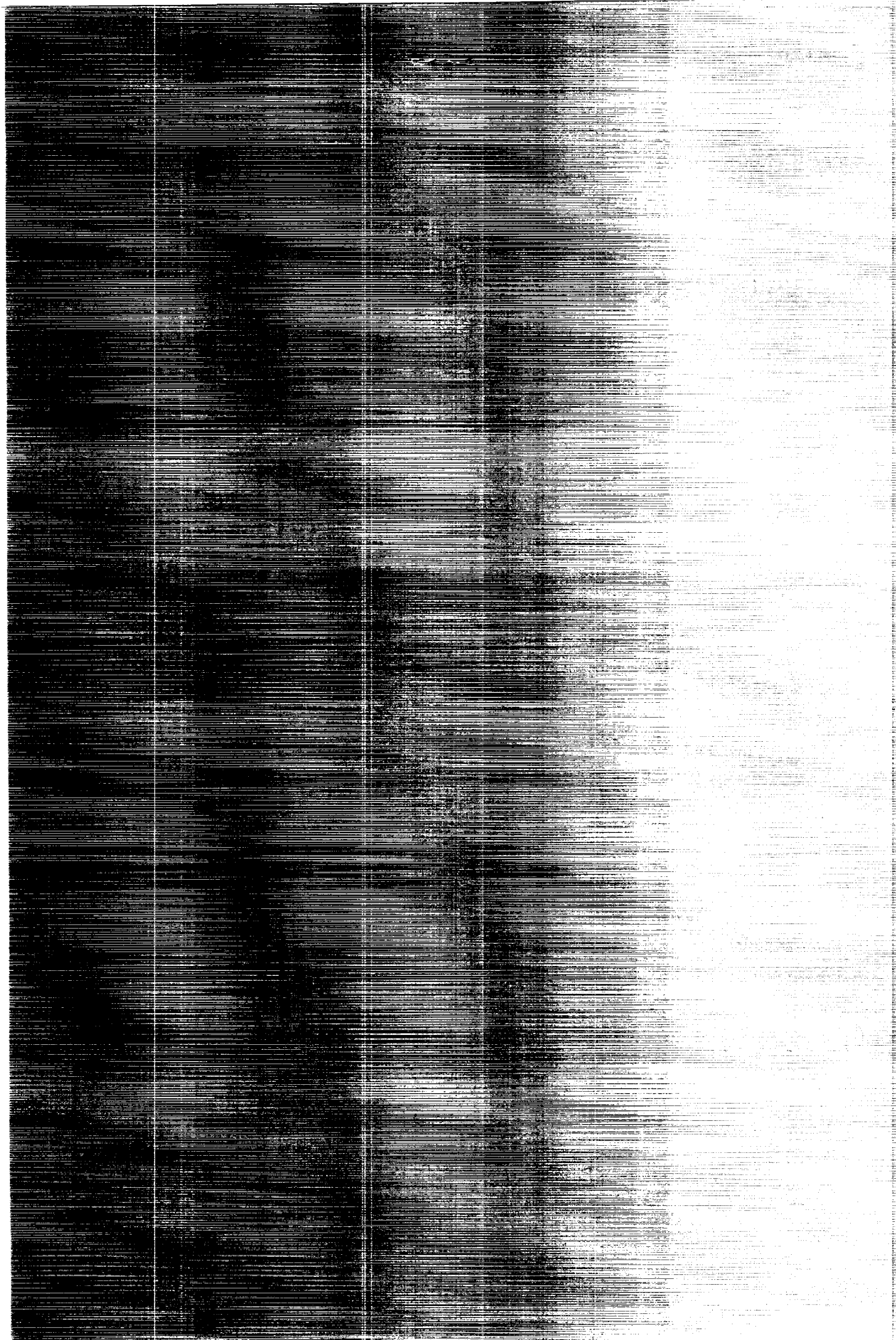


NASA Technical Memorandum 4465

\section{Summary of the Effects of Engine Throttle Response on Airplane Formation-Flying Qualities}

Kevin R. Walsh

Dryden Flight Research Facility

Edwards, California

\section{N/SA}

National Aeronautics and

Space Administration

Office of Management

Scientific and Technica

Information Program 



\title{
SUMMARY OF THE EFFECTS OF ENGINE THROTTLE RESPONSE ON AIRPLANE FORMATION-FLYING QUALITIES
}

\author{
Kevin R. Walsh* \\ NASA Dryden Flight Research Facility \\ P.O. Box 273 \\ Edwards, California 93523-0273
}

\begin{abstract}
A flight evaluation was conducted to determine the effect of engine throttle response characteristics on precision formation-flying qualities. A variable electronic throttle control system was developed and flight-tested on a TF-104G airplane with a J79-11B engine at the NASA Dryden Flight Research Facility. This airplane was chosen because of its known, very favorable thrust response characteristics. Ten research flights were flown to evaluate the effects of throttle gain, time delay, and fuel control rate limiting on engine handling qualities during a demanding precision wing formation task. Handling quality effects of lag filters and lead compensation time delays were also evaluated. The Cooper and Harper Pilot Rating Scale was used to assign levels of handling quality. Data from pilot ratings and comments indicate that throttle control system time delays and rate limits cause significant degradations in handling qualities. Threshold values for satisfactory (level 1) and adequate (level 2) handling qualities of these key variables are presented. These results may provide engine manufacturers with guidelines to assure satisfactory handling qualities in future engine designs.
\end{abstract}

\section{Introduction}

The ability to conduct such precise flying tasks as close-formation flight or aerial refueling is strongly affected by the engine throttle response, that is, thrust response caused by throttle changes. With the advent of digital engine control systems, control software has become commonly used to modify engine response characteristics. ${ }^{1}$ The engine throttle response may be degraded if such modifications are improperly

\footnotetext{
*Aerospace Engineer.

Copyright (C) 1992 by the American Institute of Aeronautics and Astronautics, Inc. No copyright is asserted in the United States under Title 17, U.S. Code. The U.S. Government has a royalty-free license to exercise all rights under the copyright claimed herein for Governmental purposes. All other rights are reserved by the copyright owner.
}

validated. No criteria for defining good or bad engine throttle response characteristics currently exist.

In the past 10 years, engine throttle response problems have been encountered in several airplanes, for example, the F-15 (McDonnell Douglas Corporation, St. Louis, Missouri) with the developmental F100 engine model derivative (Pratt \& Whitney, West Palm Beach, Florida), ${ }^{2}$ AV-8B (McDonnell Douglas Corporation, St. Louis, Missouri), ${ }^{3}$ and F-18 (McDonnell Douglas Corporation, St. Louis, Missouri, and Northrop Corporation, Hawthorne, California). Problems in these examples ranged from excessive initial time delay or lag in the F-15 and AV-8B airplanes to high throttle sensitivity in the initial F-18 installation. Such examples illustrate the need for handling quality guidelines or design specifications for advanced engine control systems. These engine design specifications are analogous to those developed over the last two decades for advanced flight control systems. As a result, data are required to develop handling qualities criteria to quantify the effects of thrust response dynamics on a pilot's ability to complete precision flight control tasks.

A brief flight research program was conducted at the NASA Dryden Flight Research Facility (DFRF) to investigate the effects of varying engine throttle response on airplane handling qualities. An electronic variable-throttle response system was developed and installed on a two-seat TF-104G airplane (Lockheed Corporation, Burbank, California). This airplane was an ideal choice because its J79-11B engine (General Electric, Lynn, Massachusetts) responds to throttle changes extremely quickly. The variable-response electronic throttle enabled the pilot to evaluate throttle system degradations and resulting effects on engine handling qualities.

This program provides initial data for developing handling qualities criteria and design guidelines for attaining satisfactory (level 1) throttle response of highperformance airplane engines. Data were obtained at one flight condition: the airspeed was $300 \mathrm{kn}$, and the 
altitude was $15,000 \mathrm{ft}$. This fight condition represents a formation-flying task.

This paper summarizes the results of the flight research program and describes the variable-throttle response system as installed in the TF-104G airplane. Time history data for the representative pilot evaluations and a compilation of pilot comments with respect to the time history data are presented. These data show the differences between satisfactory, adequate, and inadequate (level 1,2, and 3) handling qualities on the Cooper and Harper Pilot Rating Scale. ${ }^{4}$ Data showing time delay and rate limit thresholds for the different levels of handling qualities are also presented. Additional data show the effects of a first-order lag filter and of a lead-lag filter in combination with additional time delay on handling qualities.

The work of George E. Cooper and Robert P. Harper, $\mathrm{J}_{\mathrm{r}}$., is gratefully acknowledged. ${ }^{4}$ This work was instrumental in developing this engine handling qualities flight test program.

\section{Nomenclature}

$\begin{array}{ll}A X & \text { aircraft longitudinal acceleration, } g \\ g & \text { acceleration of gravity, } \mathrm{ft} / \mathrm{sec}^{2} \\ \text { HQR } & \text { handling quality rating } \\ \text { L/I } & \text { lead-lag } \\ \text { LVDT } & \text { linear variable-differential transformer } \\ \text { MTE } & \text { mission task element } \\ N 1 & \text { compressor speed, rpm } \\ \text { PCM } & \text { pulse code modulation } \\ \text { PIO } & \text { pilot-induced oscillation } \\ P L A & \text { power lever angle, deg } \\ P L A C M D & \text { power lever angle command, deg } \\ P L A F B & \text { power lever angle position feedback, deg } \\ \text { rpm } & \text { revolutions per minute } \\ \text { RVDT } & \text { rotary variable-differential transformer } \\ \text { TCU } & \text { throttle control unit } \\ \Delta T & \text { change in time delay, msec } \\ \delta x & \text { throttle position limit commanded by } \\ & \text { throttle control unit, deg } \\ \tau_{d} & \text { L/L, denominator time constant } \\ \tau_{n} & \text { L/L numerator time constant } \\ \omega_{n} & \text { second-order lag natural frequency } \\ \zeta & \text { second-order lag damping ratio }\end{array}$

\section{Airplane and Engine Description}

The test airplane was a TF-104G: a highperformance, two-place, trainer-fighter-interceptor airplane with a maximum Mach number of 2.0 .
Figure 1 shows the TF-104G airplane. Notable: features include the extremely thin flight surfaces, the short and straight wings with $10^{\circ}$ anhedral, and a controllable horizontal stabilizer mounted at the top of the vertical stabilizer. The wings have leading- and trailing-edge flaps and a boundary-layer control system used with the trailing-edge flaps to reduce landing speeds.

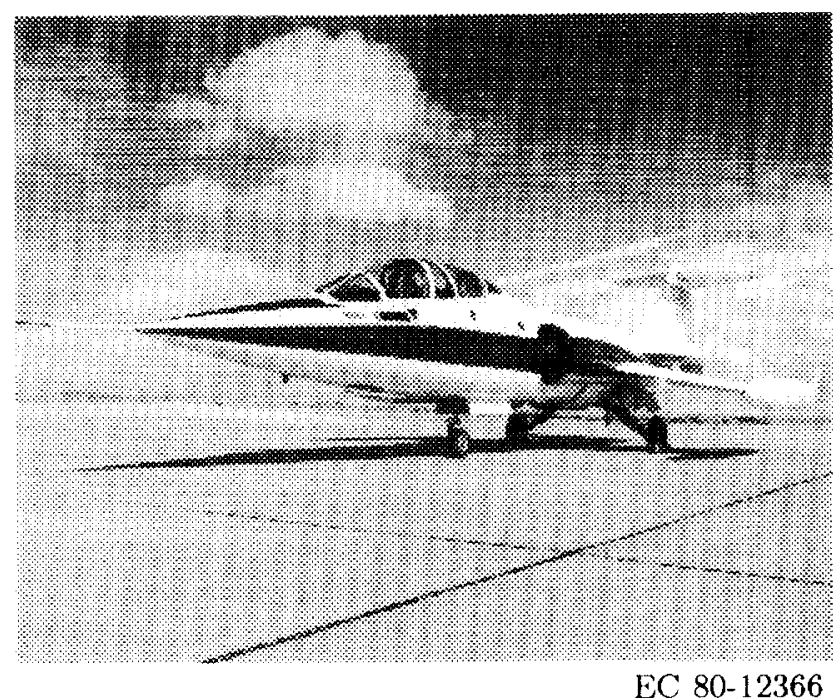

Fig. 1. The TF-104G airplane.

The $\mathbf{J} 79-11 \mathrm{~B}$ is an axial-flow, high-pressure-ratio turbojet engine with variable-inlet guide vanes, variablestator vanes, and single-rotor compressor. This engine has a cannular combustor, a threc-stage turbine, and a fully modulating afterburner with a variable-area converging and diverging exhaust nozzle.

\section{Variable-Response Throttle System Description}

The electronic variable-response throttle control systern was developed by Calspan (Buffalo, New York) specifically for the DFRF TF-104G airplane. Neal and Sengupta described the implementation and operation of the throttle control system. ${ }^{5}$ The throttle in the forward cockpit was modified to command the experimental system. Figure 2 shows the main components of the system. These components consist of an electronic throttle control unit (TCU), integrated servomotor and clutch assembly, and position sensors. A cable linkage connected the servomotor with the engine fuel controller. The throttle in the aft cockpit remained in the production configuration and served as the safety backup system.

Figure 3 shows a simplified block diagram of the modified propulsion control system. Additional throtthe system dynamics were generated by the TCU and 


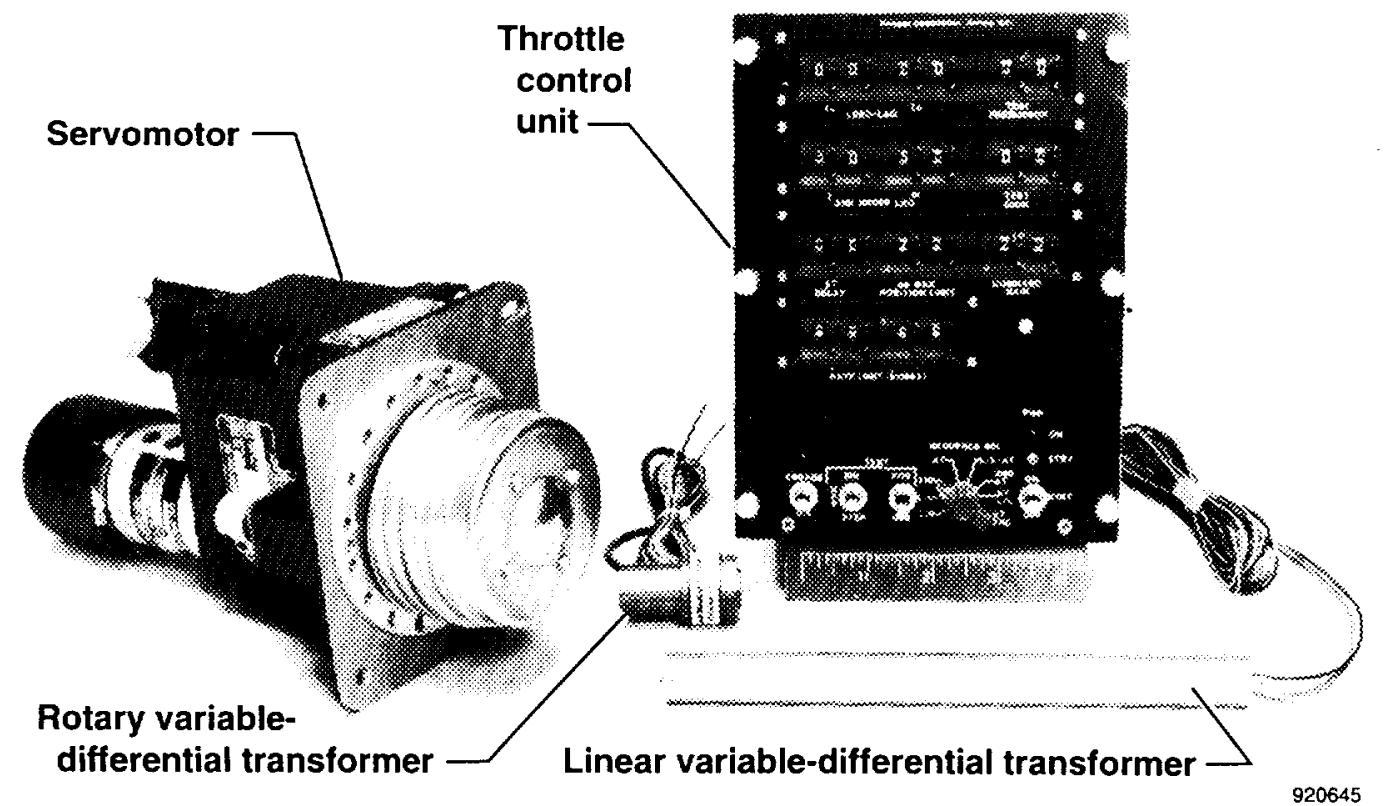

Fig. 2. Flectronic throttle system hardware.

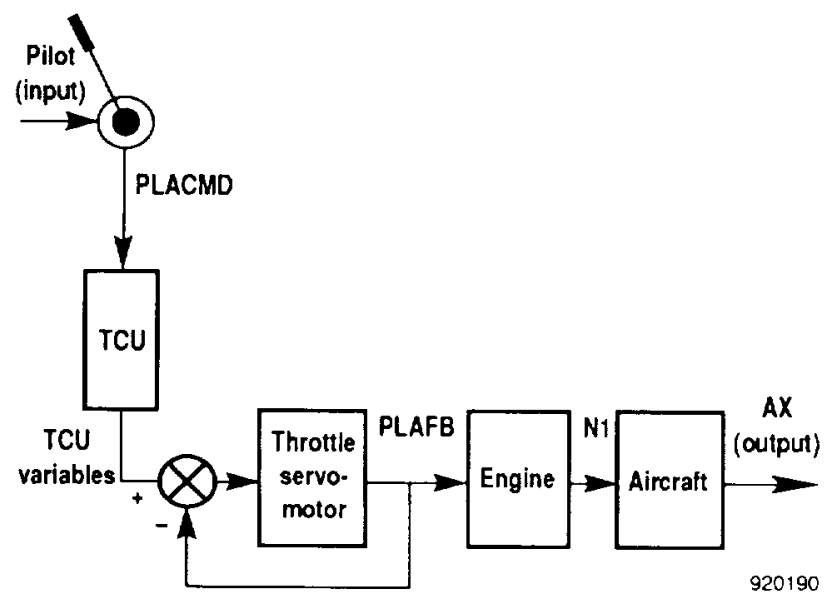

Fig. 3. Modified propulsion control system.

the servomotor. For example, the power lever angle commanded (PLACMD) by the pilot is modified by the TCU to command the servomotor. The resulting change in the power lever angle ( $P L A$ ) caused by the servomotor is the input to the fuel controller. This angle provides PLA position feedback (PLAFB) to the electronic control system. Measurements of compressor speed (N1) and aircraft longitudinal acceleration $(A X)$ are also represented. Throttle gain or sensitivity, $g / \mathrm{deg}$; transport time delay, sec; and rate limiting, $\mathrm{deg} / \mathrm{sec}$ were the primary variables for the experiment. The secondary variables included first-order lag filter time constants and lead-lag time constants.
Figure 4 shows a functional block diagram of the electronic throttle control system. The descriptors outside the polygon represent the mechanical system, and the electronic system is shown inside the polygon.

\section{Mechanical System}

In the production TF-104G airplane, a conventional cable and pulley system connects the forward and aft throttles to the engine fuel control. The two throttle handles are linked so that when one throttle handle. is moved, the other tracks its position. As a result, the position of the forward and aft throttles match at all times.

To incorporate the electronic throttle system, the forward or evaluation throttle was disconnected by removing the throttle linkage to the fuel control cables. A rotary variable-differential transformer (RVD'T) was connected to the throtlle handle through gears and installed in the throttle housing to sense forward throttle position. Disconnecting the forward throttle from the cable system eliminated the inherent friction on the throttle handle; therefore, an adjustable friction device was installed in the housing to maintain throttle feel. This device, a small phenolic block and bracket, created drag against the throttle-handle axle. The device was intended to be adjustable to any friction level; however, the throttle stick force was adjustable to a maximum of $2 \mathrm{lb}$ or approximately one-half of the normal stick force for the production throttle. 


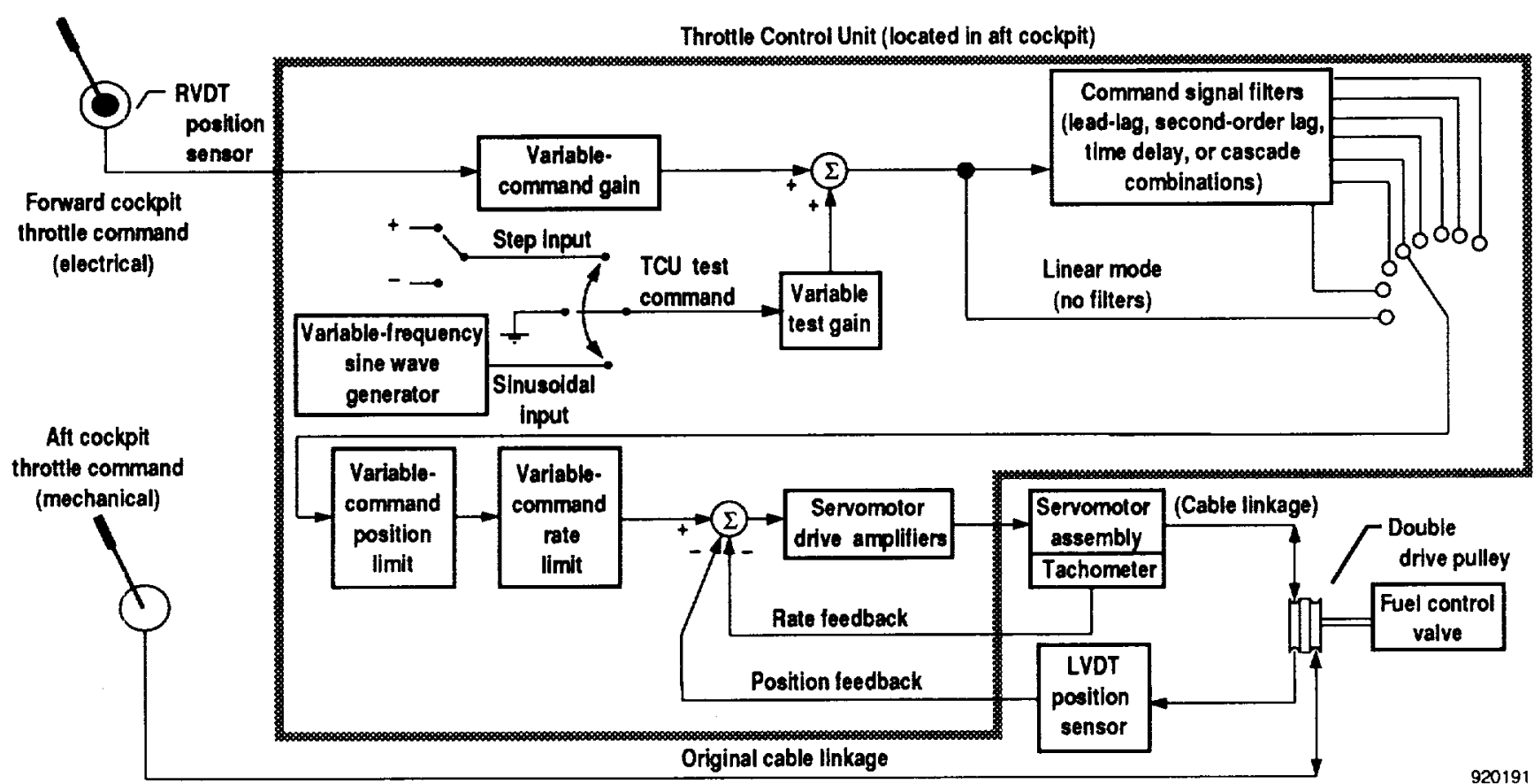

Fig. 4. The throttle control system.

A servomotor, clutch, and cable assembly was installed in the engine bay to position the fuel controller. A linear variable-differential transformer (LVDT) was used to sense $P L A$ at the fuel controller.

The TCU was installed in the left-hand console of the aft cockpit and provided the desired throttle response variations for the experiment. The backseat pilot could disengage or override the electronic throttle control system at any time. The mechanical control system was always functional from the aft cockpit. Since the aft cockpit throttle was mechanically linked to the fuel control valve, the rear throttle position tracked the throttle commands. The front seat pilot had no way to control the engine if the TCU were disengaged.

\section{Electronic System}

The block diagram inside the shaded polygon of Fig. 4 shows the electronics of the throttle control system. The RVDT generated an electrical signal which was amplified by a gain factor in the TCU. The TCU checked the amplified signal against position (amplitude) and rate limits. This signal was compared with the actual throttle position at the fuel control valve which was measured by the LVD'T. The difference between the RVDT command and the LVD' feedback signals was an error signal used to advance or retard the servomotor position. A tachometer on the servomotor assembly provided a rate feedback to the TCU. The damping characteristics of the electronic control system were optimized by adjusting the rate feedback gain.

Figure 5 shows the TCU panel which the aft pilot used to activate the system, select the operating mode, set the system variables, and enter test signals. The TCU inserted time delays, rate limits, lead-lag time constants, first- and second-order lags, and position limits into the command path. These variables acted directly on the pilot throttle commands. A rotary switch on the TCU panel was used to select the desired test variables. Thumbwheel switches on the control panel were used to set the value of the test variables. The variables could be tested individually without altering other variables. They could also be cascaded, such as testing a time delay followed by a leadlag filter. Positive and negative rate limits could be adjusted independently to simulate an engine that would increase revolutions per minute (rpm) at a different rate than it would decrease rpm. The output signal of the circuit selected was then rate and position limited.

Circuits in the TCU could selectively generate two test inputs: a step signal and a sinusoidal signal. The step input had either positive or negative polarity, and the sinusoidal input could vary from 0.0 to $2.9 \mathrm{~Hz}$. The test inputs were used during the flight program; however, the data are not presented in this paper. Refer to Ref. 5 for additional information concerning the implementation and operation of the variable-response electronic throttle system in the TF-104G airplane. 


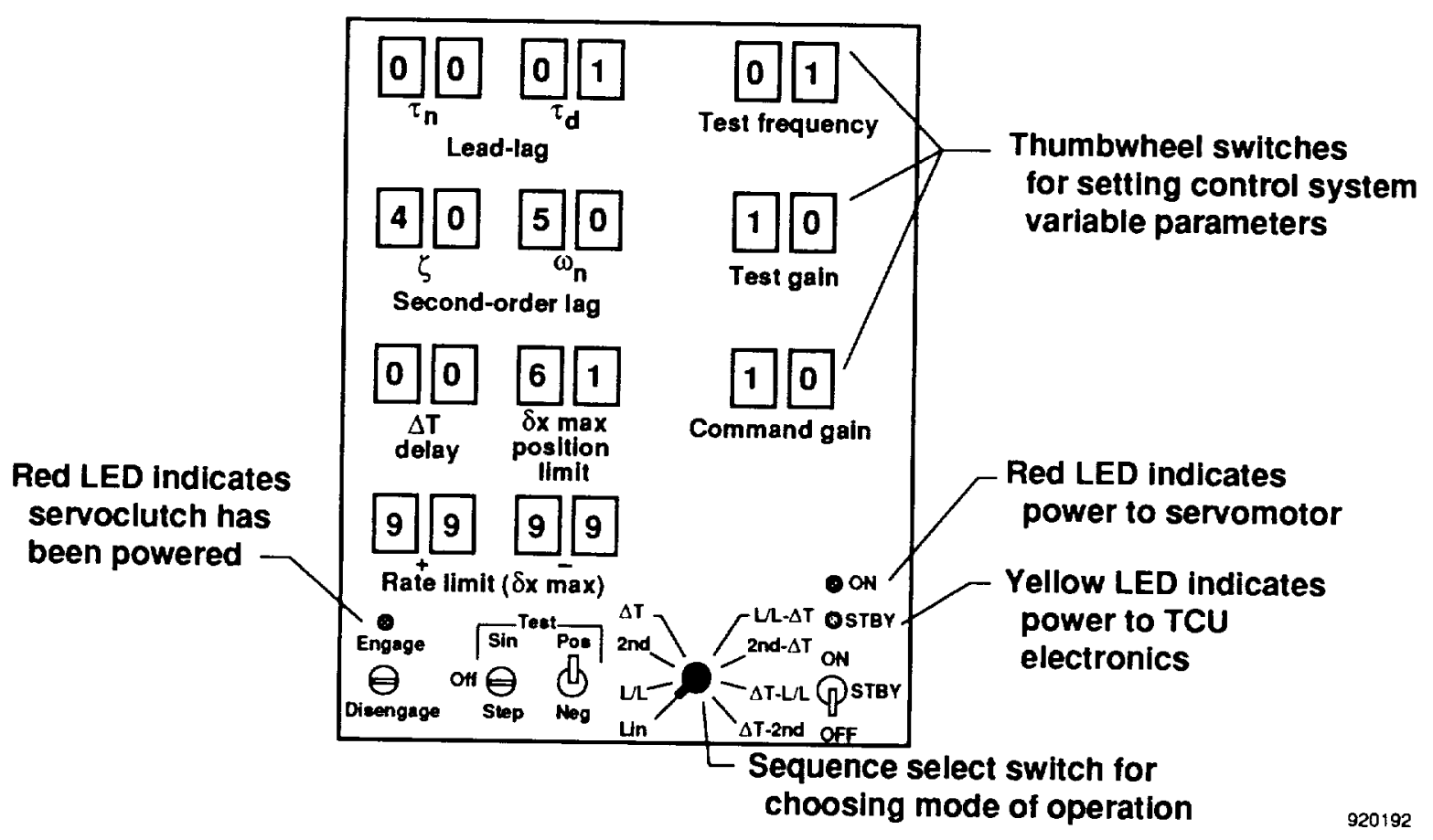

Fig. 5. The throttle control unit panel.

\section{Instrumentation}

Information from the airplane, engine, and $\mathrm{TCU}$ was obtained on a pulse code modulation (PCM) data acquisition system. The serial PCM data were telemetered to the ground, decoded and formatted for real-time display on cathode ray tubes and strip charts, and recorded for postflight analysis. Instrumented parameters were measured at $200 \mathrm{samples} / \mathrm{sec}$

Measured values of pressure and temperature were used to generate computed values of airspeed, altitude, Mach number, static temperature, and standard day temperature at altitude. These calculated parameters were also formatted for real-time display. Tables 1 and 2 in Ref. 5 show the airplane, engine, and TCU parameters that were measured for this experiment.

\section{Development of Handling Qualities Experiment}

This discussion describes the development of the electronic throttle handling qualities experiment and is based on the work of Cooper and Harper. ${ }^{4}$ To achieve reliable data and comparable ratings among the pilots, care was taken in developing the experiment objectives, mission description, mission task elements $(\mathrm{MTE})^{6}$, rating criteria, pilot assessments, and flight test procedures.

\section{Objectives}

In general, the experiment obtained highly definitive handling qualities data for a modified J79-11B engine in a TF-104G airplane. According to U.S. Air Force military specification MII-F-8785C, the TF-104G airplane, being a highly maneuverable fighter and interceptor, is considered a class IV aircraft. ${ }^{7}$

Formation flying was the mission of interest for the evaluations. The specification classifies formation flying as a category A flight phase. ${ }^{7}$ This flight phase requires rapid maneuvering, precision tracking, or precise flightpath control.

The primary variable for obtaining handling qualities data was thrust control. Other typical handling quality variables, such as airframe stability and control characteristics as well as cockpit interface elements, were not considered.

The five pilots who participated in the program were experienced in evaluating handling qualities of class IV airplanes. Their role was important in determining pilot and vehicle performance during the task. Figure 6 shows a modified Cooper and Harper Handling Qualities Rating (HQR) Scale. This scale defines satisfactory, adequate, and inadequate (level 1,2, and 3) performance.

\section{Mission Description}

The required operation for the formation-flying task was to attain and maintain fore and aft position relative to the wing of the lead airplane by using visual references. This high gain, precise, closed-loop tracking task requires the pilot to devote full-attention to airplane control and to use the throttle as the primary control input. 


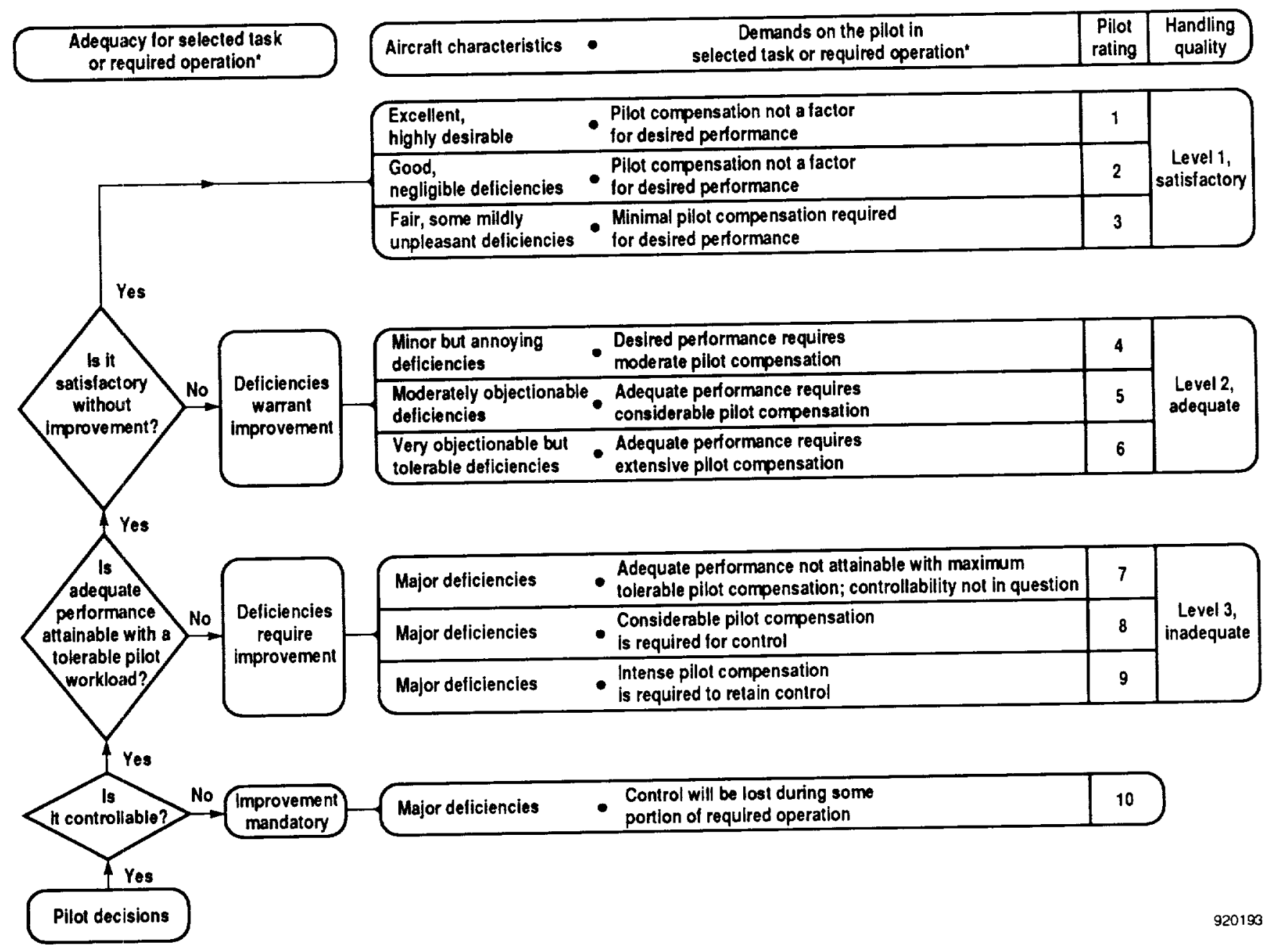

Fig. 6. Cooper and Harper Pilot Rating Scale.

The lead airplane for the formation task was either a T-38 (Northrop Corporation, Hawthorne, California) or an F-18. Nominal flight conditions used for the test program were an altitude of $15,000 \mathrm{ft}$ above mean sea level and an indicated airspeed of $350 \mathrm{kn}$. This flight condition was chosen so that throttle motion was always in partial power. Only in the worst case TCU configurations did the throttle hit the military or idle power detents.

\section{Mission Task Elements}

Developing a well-defined MTE with handling quality performance criteria reduces the uncertainties and extrapolation to the real-world equivalent required by the pilot. Having the pilots consider the real-world equivalent during the evaluation lends itself to some pilot extrapolation. Such extrapolation differs for each pilot because of variations in training, knowledge, experience, and ability to assess beyond the specific task.

The flight subphase chosen after preliminary evaluations of several formation tasks was close-wing station keeping. This subphase was intended to be representative of the precision required in similar operational tasks, such as in air-to-air refueling or close-formation flight under adverse instrument conditions. Without the introduction of suitable task perturbations to challenge the pilot and the throttle response system, the task would not provide the desired degree of handling qualities discrimination. Close-formation flight with a smooth leader does not, in itself, provide the necessary discrimination; the evaluation pilot cannot separate the optimum from the marginally acceptable cases. Note, for example, that even large relatively ponderous ships can fly accurate close formations during refueling tasks at sea.

Since the emergence of full-authority electronic engine control allows the designer some flexibility, the task must allow definition of the satisfactory (level 1) throttle response characteristics. The MTE selected, therefore, involved precision wing station keeping during small and unannounced step throttle changes by the formation leader. Further, the evaluation pilot 
was to maintain relative position at all costs. In short, the task could not be abandoned when the pilot's performance degraded. The initial transient of the lead airplane did not need to be followed exactly, but the new position was to be recaptured quickly and accurately. The real-world equivalent would be an emergency air-to-air refueling or formation recovery where it is imperative to stay in position despite turbulence or inadvertent thrust changes by the leader.

\section{Rating Criteria}

Pilot rating is a measure of the handling performance of an airplane, that is, pilot and vehicle performance. Cooper and Harper define performance as "the precision of control with respect to airplane movement that a pilot is able to achieve in performing a task." 4 For this flight evaluation, the pilot ratings were applied to the MTE as previously described and were based on how quickly and accurately the evaluation pilot acquired and maintained formation position. The precision of control required by the pilot to maintain formation was an approximately 5 - $\mathrm{ft}$ wingtip clearance in the horizontal plane.

Figure 7 shows an example of the precision and performance requirements for obtaining adequate pilot performance for the MTE. The following criteria were applied for obtaining the HQR:

- Satisfactory performance was $\pm 1 \mathrm{ft}$ with one overshoot allowed.

- Adequate performance was $\pm 3 \mathrm{ft}$ with two overshoots allowed.

Another important consideration for determining HQR was pilot workload. Cooper and Harper define pilot workload as "the integrated physical and mental effort required to perform a specified piloting task." 4 In this case, physical effort is the motions and forces imposed on the throttle by the pilot during the MTE.

No auxiliary tasks were required during the MTE so that only thrust control characteristics were evaluated. Additional workload imposed by auxiliary tasks would have interfered with the pilots' evaluation of the thrust control characteristics.

\section{Pilot Assessments}

Cooper and Harper note that the pilot rating is a "shorthand representation of the handling qualities of an airplane in the performance of a defined mission and task." ${ }^{4}$ The evaluation pilot continuously considered the rating decision process to obtain the pilot rating during the MTE. This process involves a series of dichotomous decisions based on the adjective descriptors of the pilot rating scale (Fig. 6).
Pilot ratings of one-half (for example, PR 4.5) indicate an indecision or reluctance to assign either of the adjacent ratings to describe the throttle configuration. Ratings of $3.5,6.5$, and 9.5 are generally not used because they represent important boundary conditions. The boundary conditions are based on yes or no decisions to obtain satisfactory, adequate, or inadequate (level 1,2 , or 3 ) handling qualities.

Pilot comments were recorded during the evaluations to avoid having the HQR represent the entire qualitative assessment. Pilot comments are one means of identifying good or deficient qualities of a configuration. During an evaluation, the pilots reported what they saw and felt and described their difficulties in completing the MTE. Such comments were in response to a questionnaire developed for the MTE. All evaluation pilots participated in preparing the questionnaire. This questionnaire helped ensure that important or suspect aspects were considered, the reason for the assigned rating was given, the tradeoffs that the pilot must contend with were understood, and any supplementary comments that help describe the pilots' evaluation of the configuration were provided.

\section{Flight Test Procedures}

The backseat pilot acted as the test conductor and safety pilot for the research flights. Throttle configurations were defined for evaluation according to the mission plan before each test flight. These configurations were written on flight cards for the backseat pilot to use in selecting the TCU settings. This pilot could disengage the variable-throttle response system at any time and use the unmodified rear cockpit throttle. In an emergency, this pilot could also overpower the throttle system servomotor to command the desired throttle inputs.

The evaluation pilots were unaware of the TCL configuration during the MTE evaluations. This methodology was used to avoid pilot preconceptions of what effect such configurations as throttle time delay would have on airplane handling qualities.

Each throttle configuration was evaluated in two stages. The set up of each test configuration was made: with significant distance between the test and lead airplanes. After entering the test configuration, the evaluation pilat maneuvered into a close-formation position with the lead airplane. The pilot evaluated the throttle control system during the join-up and formation phases of the maneuver until satisfied that a valid HQR could be made. Then upon command from the evaluation pilot, the lead airplane began a series of small, random throttle excursions called throttle jinks. These throttle jinks increased or decreased the separation distance and the rate of separation. The evaluation pilot's tasks 


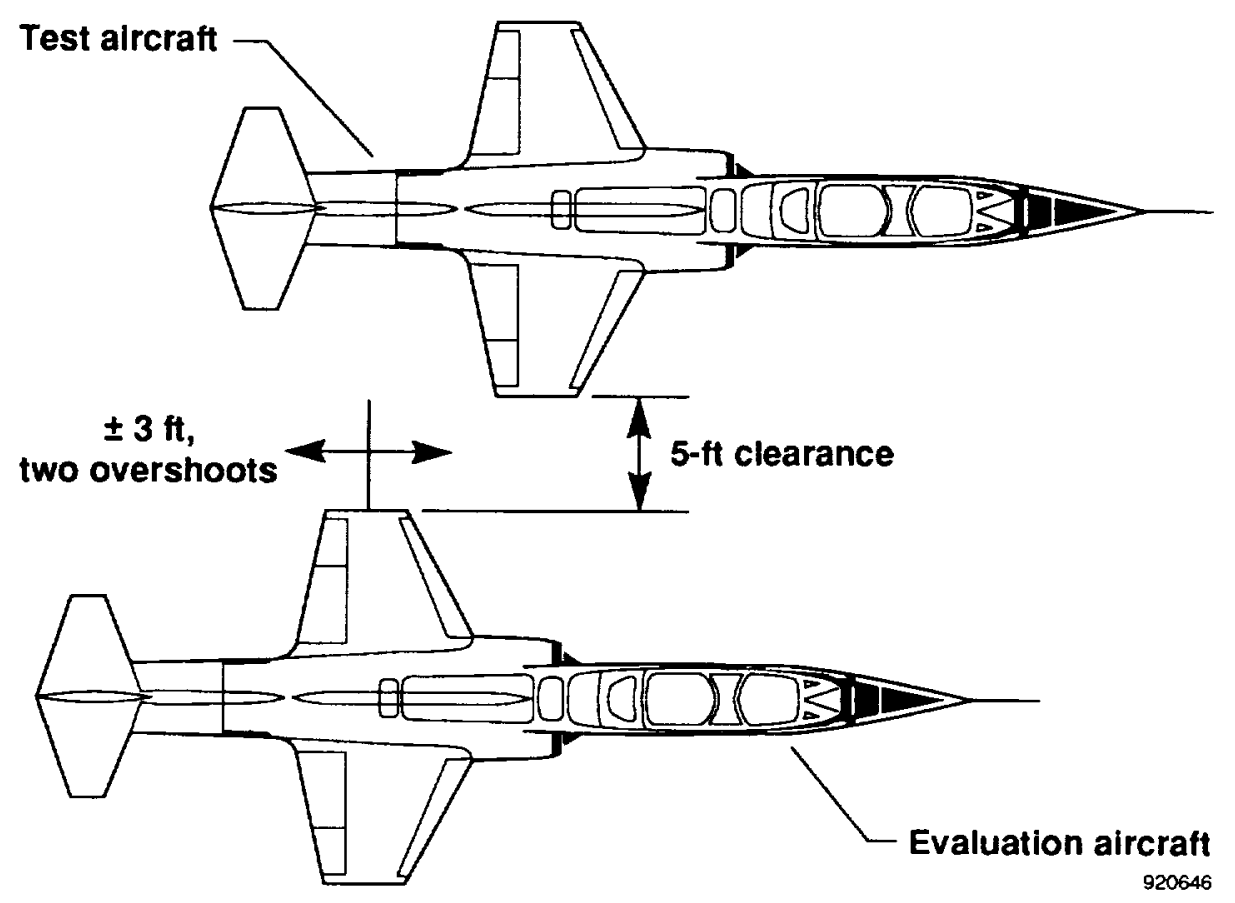

Fig. 7. Precision and performance requirements for adequate pilot performance.

were to aggressively reacquire and maintain the initial separation and to evaluate the task as previously described. This pilot provided comments pertinent to the questionnaire during the evaluation.

The evaluation pilot briefly returned to the so-called benchmark configuration between each MTE. Note that the evaluation pilot knew that this was the benchmark configuration. This configuration was essentially the basic $\mathrm{J} 79-11 \mathrm{~B}$ engine (that is, the TCU in linear mode) modified by the throttle servodynamics, optimum throttle control gain, and change in throttle friction. Evaluation pilots had the option of re-flying the task in the benchmark configuration to ensure quality control of each evaluation. Afterward, the pilots could change the HQR, but they rarely made such changes. Since 10 to 14 evaluations were performed during each flight, this benchrnark procedure helped the pilots to retain a good reference standard.

Upon completion of the task, control was returned to the backseat pilot. Then, the evaluation pilot assigned an HQR and provided more comments regarding the performance of the configuration.

\section{Flight Test Results and Discussion}

Five pilots flew 10 flights to evaluate the electronic throttle control system. Two of the flights were flown to check the variable-throttle response system functionally, define the MTE, critique the manner in which the task was performed, and evaluate the pilots' assessment of the task. Only data from four of the pilots are presented in this paper because the data from the fifth pilot does not apply to the results discussed. During the flight test program, 113 data points consisting of pilot ratings and comments were gathered.

The primary goals of the flight test program were to investigate the thrust control sensitivity effects of throttle gain, time delay, and rate limiting on airplane handling qualities. In addition, the insertion of the electronic throttle control system changed the baseline throttle system dynamics. Such changes needed to be quantified. Secondary goals were to investigate the effects of first-order lag filter time constants as well as lead-lag filter time constants. Although the primary goals were met, insufficient data were available to draw conclusions about the secondary goals.

Time history data are presented for the representative pilot evaluation tasks. In addition, a compilation of pilot comments with respect to the time history data is shown. These data show the differences between satisfactory, adequate, and inadequate (level 1,2, and 3) handling qualities (Fig. 6). Data showing time delay and rate limit thresholds for the different levels of handling qualities are also presented. The modified airplane response with the electronic throttle control system as well as the effects of throttle gain, time delay, rate limiting, lag filter, and lead-lag filter on engine handling qualities are discussed next. 
Airplane Response With Electronic Throttle Control System

The dynamics of the electronic throttle control system (Fig. 3) were estimated by applying frequency response analysis to flight test data. Determining what added effect the throttle servomotor had on system response was important. The throttle servoloop represents a feedback control system. Although its components were known, the equivalent input and output dynamics were best estimated from flight test data.

An estimate of the airplane acceleration response to throttle inputs, including the servomotor, was reasonably modeled as a first-order lag with a pure time delay within the frequency range of interest to the task. The baseline break frequency and time delay which applied to the benchmark configuration were then estimated as first-order break frequency $=5.7 \mathrm{rad} / \mathrm{sec}=0.91 \mathrm{~Hz}$, and time delay $=65 \mathrm{msec}$. The $65-\mathrm{msec}$ time delay of the throttle system is included in the time delay stated for the following data analysis discussions.

Throttle friction force was maintained at approximately $2 \mathrm{lb}$ for the experiment. This value was somewhat light when compared with approximately $5 \mathrm{lb}$ of force for the standard TF-104G throttle system. Pilots commented about the lack of friction in the evaluation throttle throughout the flight test program, but they did not think it was a factor.

\section{Throttle Gain Effect}

The throttle gain was initially evaluated to select the optimum gain value. The optimum throttle command gain for this electronic throttle control system was determined to be 1.5. This command gain closely resembled the baseline response of the standard TF-104G airplane. This value was then used as the benchmark configuration and in the majority of the evaluation configurations. The following table shows the number of evaluations and the average of all the HQR's for the given command gain:

\begin{tabular}{ccc}
\hline Gain setting & No. of evaluations & HQR \\
\hline 1.0 & 5 & 4.60 \\
$1.5^{*}$ & 15 & 2.65 \\
1.7 & 1 & 4.00 \\
2.0 & 4 & 4.25 \\
\hline
\end{tabular}

"This gain equates to $0.008 \mathrm{~g} / \mathrm{deg}$ of throttle motion for the nominal TF-104G gross weight of $18,500 \mathrm{lb}$ $( \pm 2,500 \mathrm{lb}$ variation during a flight $)$.

\section{Throttle Time Delay Effect}

The effects of additional time delay are summarized in Fig. 8 showing HQR plotted as a function of time delay. The data at $65-\mathrm{msec}$ time delay represent the

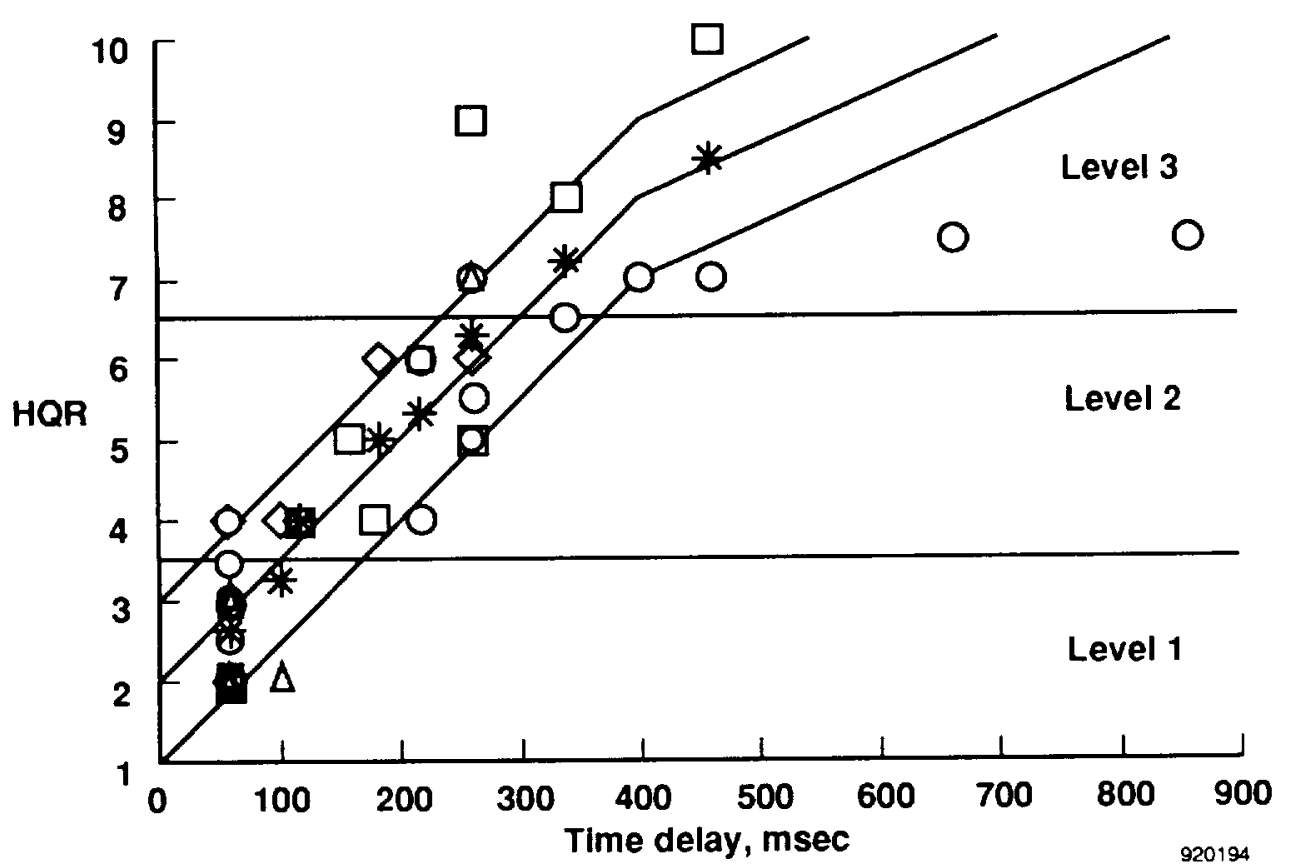

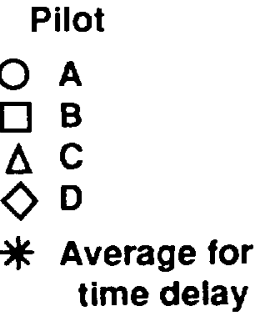

Fig. 8. Effect of throttle control system time delay on pilot rating for command gain $=1.5$ and rate limit $= \pm 99$ $\mathrm{deg} / \mathrm{sec}$. 
benchmark configuration. This 65 -msec time delay accounts for the throttle servomotor and the airplane which was previously estimated. Rate limit was set for $\pm 99 \mathrm{deg} / \mathrm{sec}$ for all time delay evaluations.

The data trend shows a steep degradation of HQR with added time delay. A \pm 1 HQR band was superimposed on the data. Approximately 90 percent of the data falls within this band. Significant thrust pilotinduced oscillations (PIO's) occurred during the evaluation task for time delay values greater than $250 \mathrm{msec}$. Data from this experiment suggest the following time delay thresholds:

- Level 1 time delay $<100$ msec $(H Q R \leq 3.5)$.

- Level 2 time delay < 300 msec $(3.5 \leq$ HQR 6.5$)$.
Several cases were evaluated where the throttle gain was changed to determine if the handling quality effects of a time delay could be minimized. No trends could be established for the limited cases studied. Apparently, time delay problems could not be solved by suitable command gain changes. Note, however, that a throttle command gain of 1.5 was chosen as optimum with an inherent time delay of $65 \mathrm{msec}$ and a hysteresis loop. All pilots commented that except for the lack of friction, this configuration responded similarly to the standard TF-104G airplane.

Figure 9 shows time histories and piloting comments representing satisfactory (level 1) handling qualities for a time delay of $65 \mathrm{msec}$. The parameters are throttle command, throttle feedback, compressor speed, and

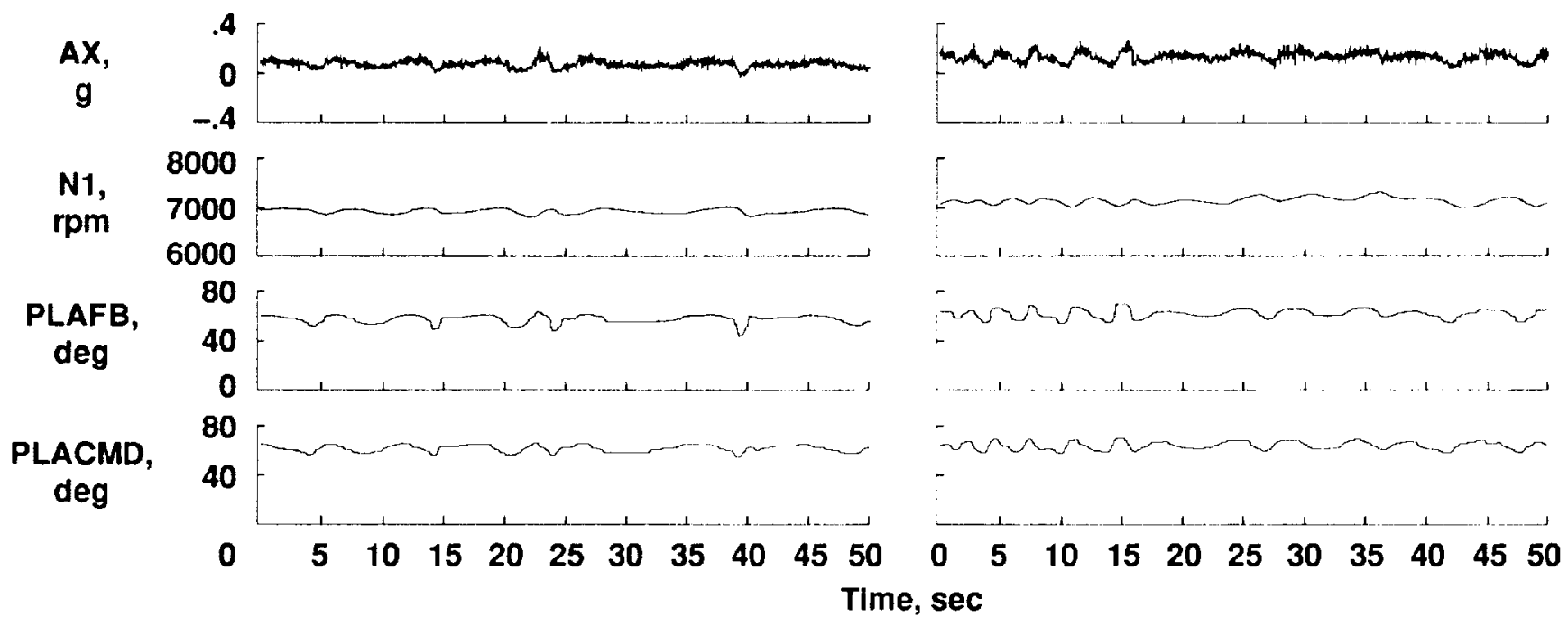

(a) Time histories of pilot $\mathrm{A}, \mathrm{HQR}=3.0$.

(b) Time histories of pilot $\mathrm{B}, \mathrm{HQR}=2.0$.

Pilot $\quad \mathrm{HQR}$

Comments

A

I guess there was no time delay. Performance was as desired. Most of the time, I was within a foot and seldom had an overshoot.

B $\quad 2.0$

Good response for the throttle inputs I put in. Easy to fine tune final position with small inputs. When I follow the lead airplane's thrust changes, it takes me a cycle or two to get in phase with it. That's probably more my technique than anything.

$\mathrm{C} \quad 3.0$

Very responsive. Able to track changes very well, however, there is a little bit of delay in the initial response compared to perfection. The initial response requires a little compensation, like a quick overdrive of the throttle to catch the rate and move into position.

$\mathrm{D} \quad 2.0$

Good relationship between throttle angle and rpm change. Not much apparent hysteresis. Would prefer more friction in the throttle $-\mathrm{I}$ am used to working against the friction with the standard F-104 airplane.

Fig. 9. Level 1 handling qualities for time delay $=65 \mathrm{msec}$ and rate limit $= \pm 99 \mathrm{deg} / \mathrm{sec}$. 
longitudinal acceleration. Note the small amplitude and low frequency of the throttle command. Pilots commented that the throttle was very responsive and that it was easy to control fore and aft position. In addition, they noted a good relationship between the throttle angle and engine rpm.

Figure 10 shows time history data representing adequate (level 2) handling qualities for a time delay of $225 \mathrm{msec}$. The parancters are the same as in Fig. 9. Note the amplitude and frequency increase of the throttle command. Pilot A recognized the time delay, and pilot $\mathrm{B}$ interpreted the configuration as a lag. Pilot $A$ evaluated the 225 -msec configuration twice. The first time, pilot $A$ did not have difficulty compensating for the delay. The second time, pilot A required extensive compensation to complete the task. Pilot $B$ reported adequate performance but only with extensive pilot compensation. This pilot could not be precise about the task, especially when the lead airplane changed thrust.

Figure 11 shows time history data for inadequate (level 3) handling qualities for a time delay of $465 \mathrm{msec}$. The amplitude of the throttle command increased, while the frequency decreased. Both pilots moved the throttle around a great deal and were unsure how to compensate for this configuration. Performance was inadequate. Pilot $A$ 's airplane oscillated more than $\pm 3 \mathrm{ft}$ with more than two overshoots. Pilot B moved

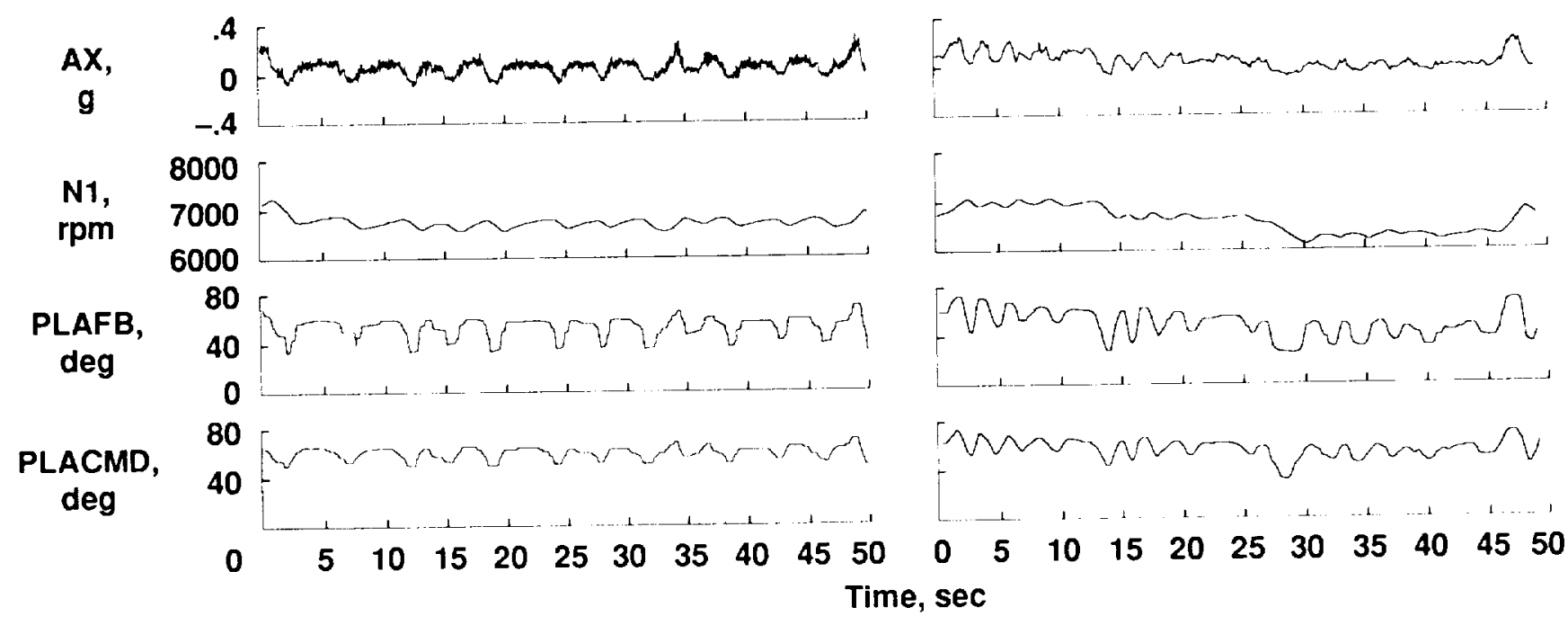

(a) Time histories of pilot $\mathrm{A}, \mathrm{HQR}=6.0$.

(b) Time histories of pilot $\mathrm{B}, \mathrm{HQR}=6.0$.

Pilot $\quad \mathrm{HQR}$

Comments

A

(a) A small delay occurs, but I'm not having any difficulty compensating. Gross acquisition is great; fine tracking is not all that bad. Desired performance achieved with moderate compensation.

A

(b) I think there's a time delay here, and this delay causes a great deal of pilot compensation to do an adequate job. There may be some rate deficiencies too. I was working just about as hard as I could and still just barely hung in there.

B $\quad 6.0$

Seems like there's some lag there. I don't detect it so much by the vibration and the sounds - the audio cues that I think I use in flying formation and a feel for power changes. Scems like I put the throttle in a position to respond, and then a little bit later the airplane moves and seems to catch up. Then I'm backing the throttle in the other direction. I'm not in a classic PIO, but I seem to be just moving back and forth slowly. I can't be precise about the task, especially when the lead aircraft is changing thrust. I guess I can adequately perform but only with extensive pilot compensation.

Fig. 10. Level 2 handling qualities for time delay $=225 \mathrm{msec}$ and rate limit $= \pm 99 \mathrm{deg} / \mathrm{sec}$. 


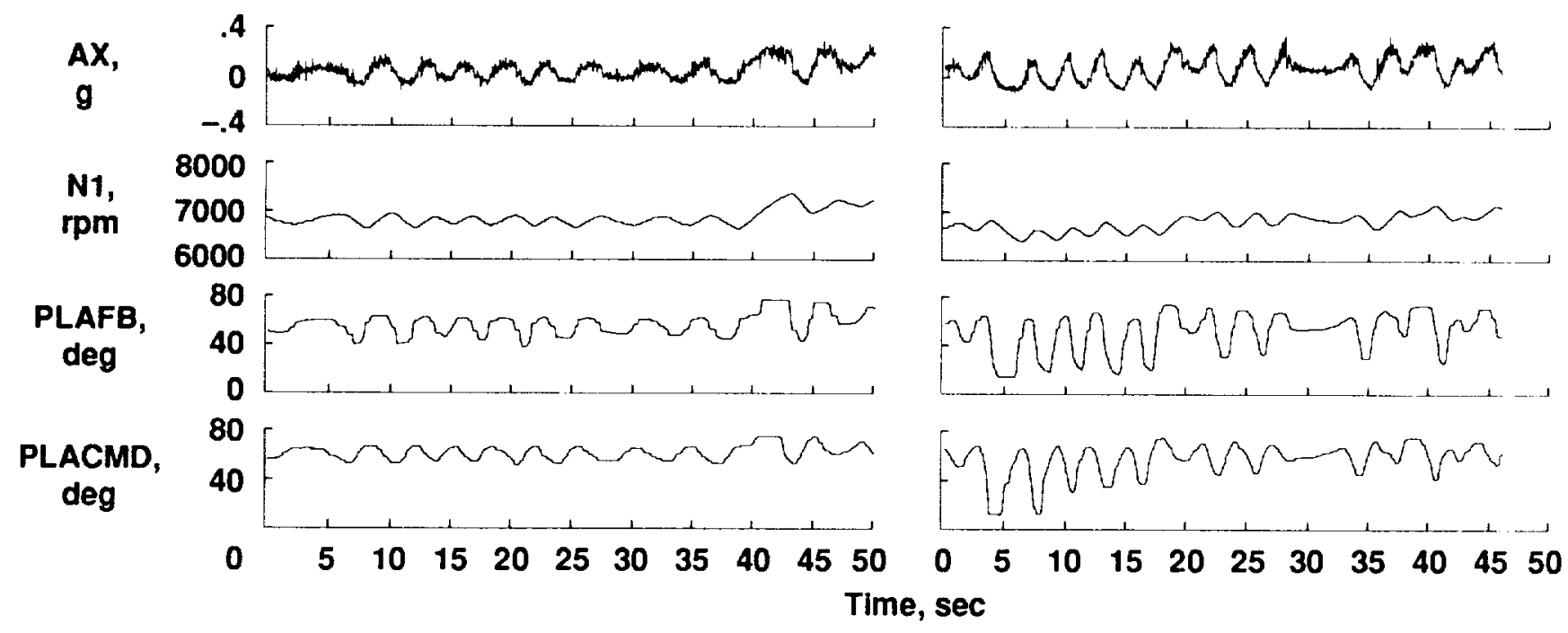

(a) Time histories of pilot $\mathrm{A}, \mathrm{HQR}=7.0$.

(b) Time histories of pilot $\mathrm{B}, \mathrm{HQR}=10.0$.

Pilot

A

B $\quad 10.0$
$\mathrm{HQR}$

7.0
Comments

Working the throttle, experiencing some throttle overshoots, but don't see much airplane motion fore and aft. Don't understand this - isn't what I thought a time delay would look like. Performance was not adequate - greater than $\pm 3 \mathrm{ft}$ with more than two overshoots.

At first, I didn't think it was all that bad, but after the lead aircraft started making throttle changes, I broke loose. I'm just oscillating, moving the throttle all around. Once I get in position, I'm not sure what's going on. Seems like a big lag moving fore and aft on the lead airplane a lot more than I'd be comfortable with.

Fig. 11. Level 3 handling qualities for time delay $=465 \mathrm{msec}$ and rate limit $= \pm 99 \mathrm{deg} / \mathrm{sec}$.

fore and aft on the lead airplane to the point of becoming uncomfortable. Inability to stay with a tanker caused pilot $\mathrm{B}$ to rate this configuration as a 10.0.

\section{Throttle Rate Limiting Effect}

To investigate the effect of throttle system rate limit on engine handling qualities, the rate at which the throttle could be commanded was progressively reduced from that of the benchmark configuration. The benchmark rate limit was $\pm 99 \mathrm{deg} / \mathrm{sec}$, and the lowest limit tested was $\pm 10 \mathrm{deg} / \mathrm{sec}$. For example, throttle position can change $10^{\circ}$ in $1 \mathrm{sec}$ for a step input with a $\pm 10 \mathrm{deg} / \mathrm{sec}$ rate limit. The commanded longitudinal acceleration in this example would be $0.008 \mathrm{~g} / \mathrm{sec}$ for the first second at the nominal TF-104G weight of $18,500 \mathrm{lb}$ and throttle gain of 1.5 .

Figure 12 shows the results of the rate limit evaluations. The HQR is plotted as a function of throttle control system rate limit. The data point at \pm 99 $\mathrm{deg} / \mathrm{sec}$ rate limit is for the benchmark configuration. Note that decreasing throttle rate limits to $\pm 45 \mathrm{deg} / \mathrm{sec}$ produced minimal change in engine handling qualities. These data indicate a sharp degradation in handling qualities with rate limit values of less than $\pm 40 \mathrm{deg} / \mathrm{sec}$. The HQR's at $\pm 40 \mathrm{deg} / \mathrm{sec}$ ranged from 2 to 6 , thereby suggesting an initial handling quality degradation. Significant PIO occurred for rate limits less than $\pm 25 \mathrm{deg} / \mathrm{sec}$. Suggested threshold rate limit values are as follows:

- Level 1 rate limit $> \pm 40 \mathrm{deg} / \mathrm{sec}(\mathrm{HQR} \leq 3.5)$.

- Level 2 rate limit $> \pm 30 \mathrm{deg} / \mathrm{sec}(3.5<\mathrm{HQR} \leq$ $6.5)$.

Figure 13 shows time history data representing adequate (level 2) handling qualities for a rate limit of $\pm 40 \mathrm{deg} / \mathrm{sec}$. The parameters are the same as in Figs. 9 to 11 . Note that the amplitude and frequency of the throttle command is approximately the same as adequate (level 2) handling qualities with additional time delay (Fig. 11). Pilot A evaluated the $\pm 40-\mathrm{deg} / \mathrm{sec}$ configuration twice. The first time, pilot $\mathrm{A}$ did not have 


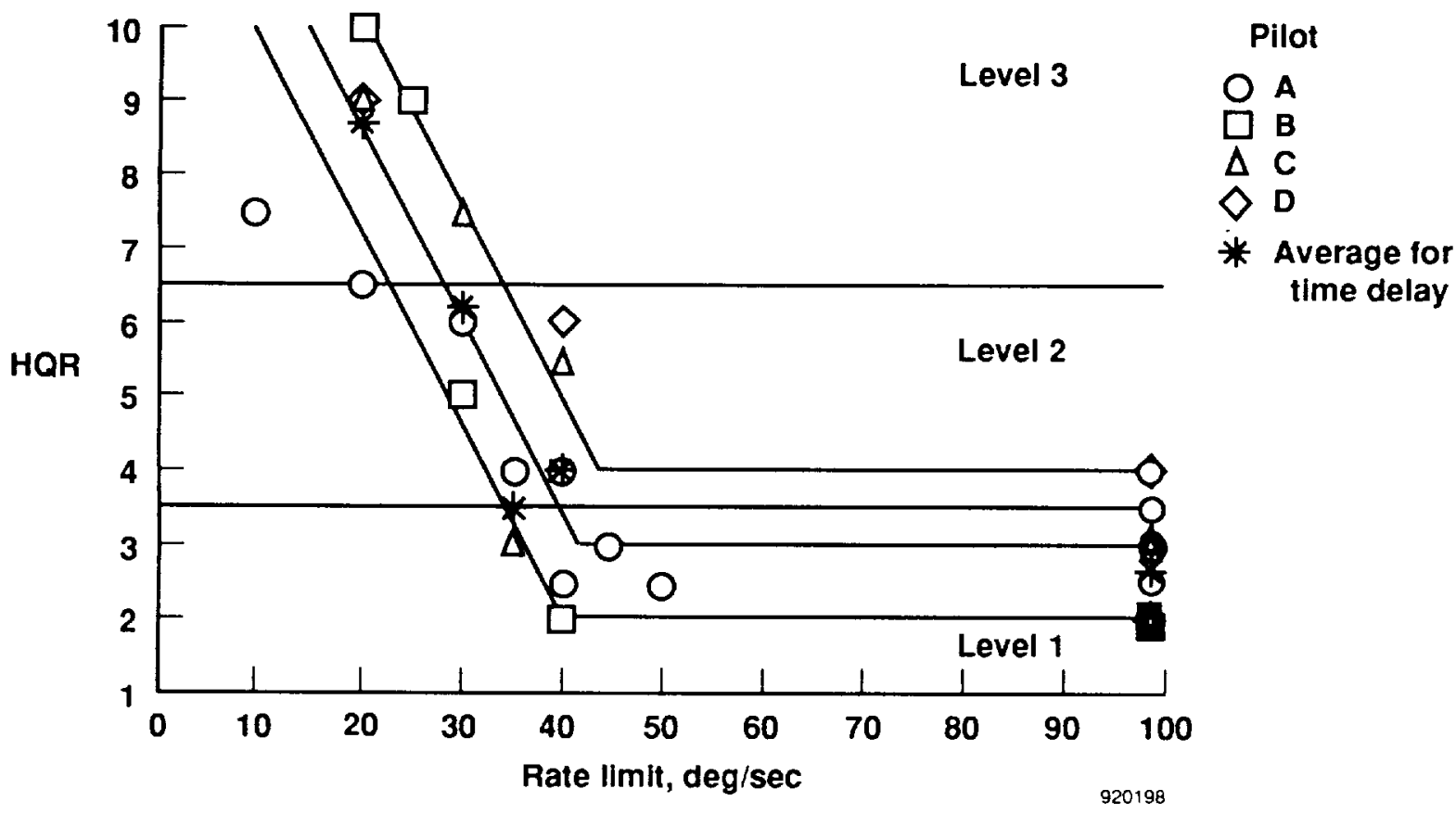

Fig. 12. Effect of throttle rate limiting on pilot ratings for throttle time delay $=65 \mathrm{msec}$ and command gain $=1.5$.

difficulty compensating for the rate limit and rated the task as a 2.5. The second time, pilot $A$ interpreted the rate limit as reduced gearing (Fig. 13(a)). Moderate pilot compensation was required to obtain desired performance, so an HQR of 4.0 was given. Pilot $C$ had difficulty anticipating the amount of throttle motion required when the lead airplane made power changes (Fig. 13(b)). Controllability was not in question, so an HQR of 5.5 was given based on pilot workload. Pilot $D$ said that at times the engine response was pretty decent but otherwise there was a tendency to overcontrol (Fig. 13(c)). The final response was unpredictable; however, the airplane was controllable with adequate performance, so an HQR of 6.0 was given.

Figure 14 shows time history data of inadequate (level 3) handling qualities for a rate limit of $20 \mathrm{deg} / \mathrm{sec}$. The amplitude of the throttle command increased significantly, often from throttle stop to throttle stop while the frequency decreased. Pilot B experienced a PIO tendency and moved the throttle from stop to stop in attempts to get the required engine response (Fig. 14(a)). Because a pilot would not be able to stay on a tanker boom in such cases, an HQR of 10.0 was given. Pilot $\mathrm{C}$ could not achieve adequate performance and thought that someone could be hurt, so an HQR of 9.0 was given (Fig. 14(b)). Pilot D commented that the initial response was slow (Fig. 14(c)), noted that there was some time delay, and was unable to obtain original formation position. Pilot D was never able to position the throttle to obtain the desired response. The PIO was in the form of moving the throttle with no apparent effects. There was no question that a tanker would have been damaged, so an HQR of 9.0 was given.

Asymmetric rate limits were tested in addition to the symmetric rate limits. The lower rate dominated the evaluation in each case. Pilot ratings and comments were comparable to those given for symmetric rate limits. For example, a 99 and $-20-\mathrm{deg} / \mathrm{sec}$ rate limit resulted in inadequate (level 3 ) handling qualities.

By combining the pilot ratings for time delay and rate limit (Figs. 8 and 12), boundaries were approximated to describe level 1, 2, and 3 handling qualities. Figure 15 shows the level of handling quality boundaries for rate limit versus time delay. The boundary for level 1 handling qualities is well defined such that throttle time delay should be less than $100 \mathrm{msec}$, and rate limit should be greater than $40 \mathrm{deg} / \mathrm{sec}$. The outer boundaries between levels 2 and 3 and between level 3 and uncontrollable are not well defined and vary greatly between pilots. As a result, the outer boundaries shown in Fig. 15 represent rough estimates.

\section{Lag Filter Effect}

The effects of first-order lag filters on the throttle response handling qualities were evaluated. Unfortunately, an insufficient number of lag time constants were tested to investigate a suitable range of handling qualities.

Figure 16 shows the effect of first-order lag filters on pilot ratings. Except for one test point, the data resulted in inadequate (level 3) handling qualities. The 


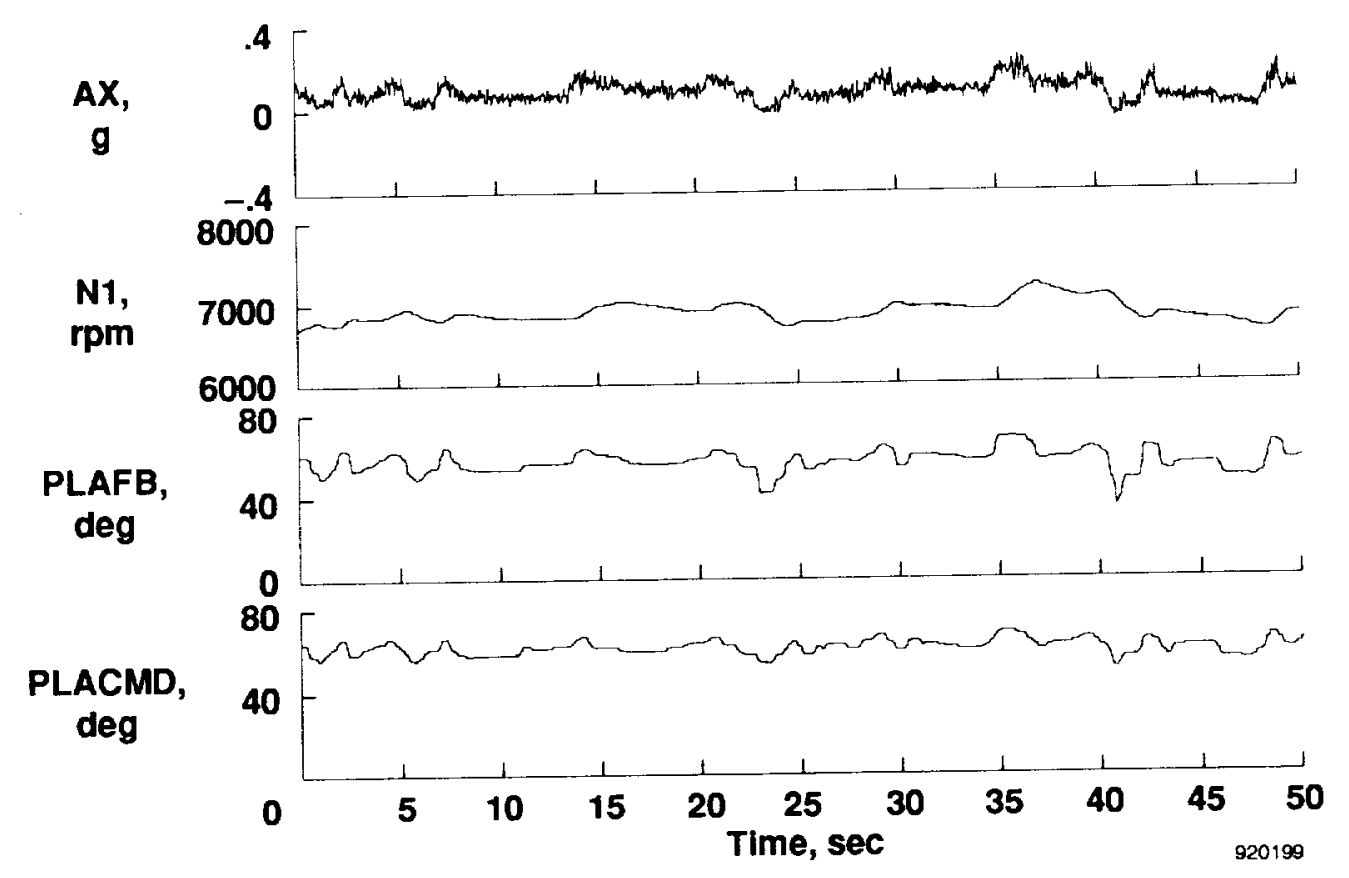

(a) Time histories of pilot $\mathrm{A}, \mathrm{HQR}=4.0$.

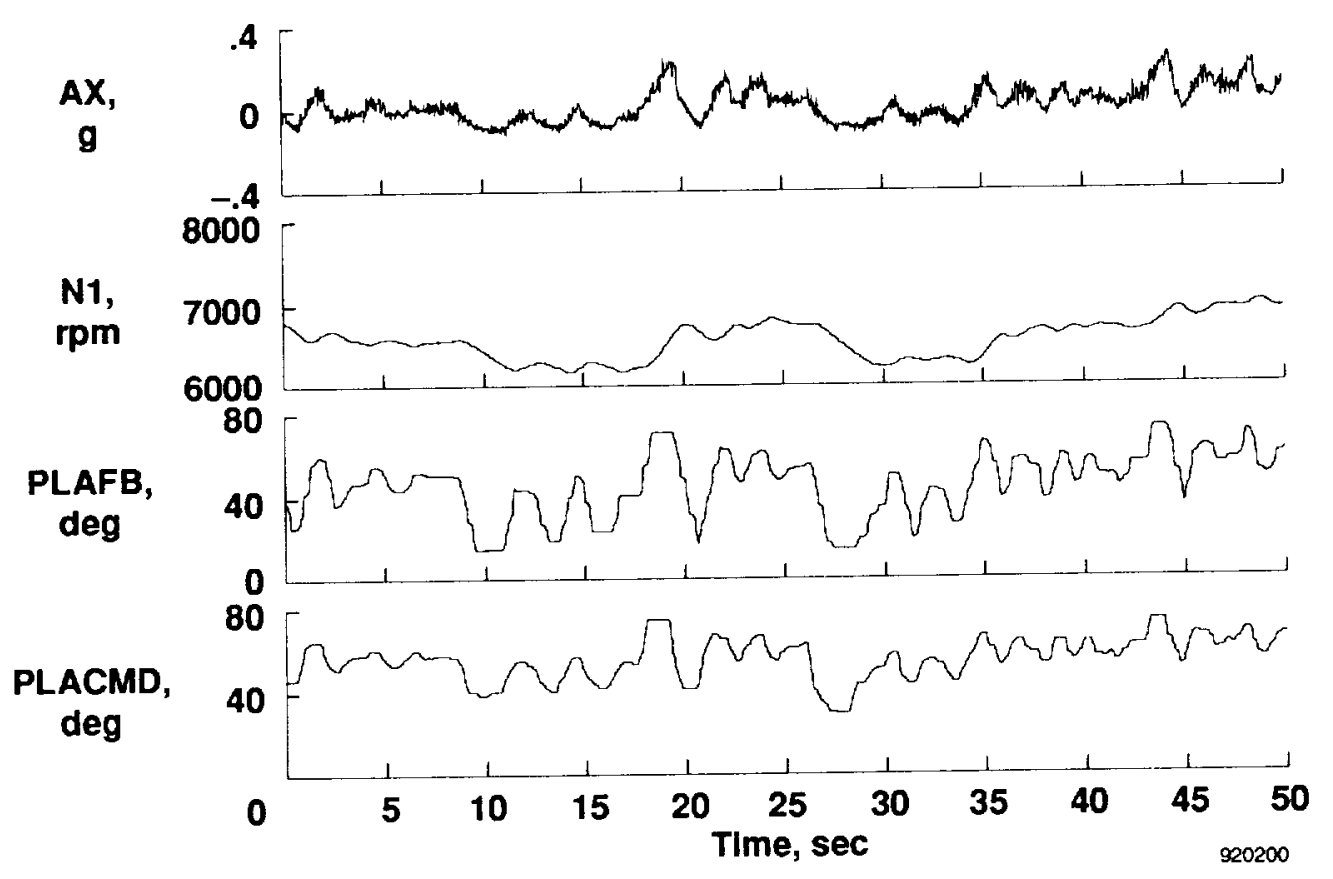

(b) Time histories of pilot $\mathrm{C}, \mathrm{HQR}=5.5$.

Fig. 13. Level 2 handling qualities for rate limit $= \pm 40 \mathrm{deg} / \mathrm{sec}$ and time delay $=65 \mathrm{msec}$.

same $\pm 1 \mathrm{HQR}$ band obtained from the time delay evaluations (Fig. 8) was superimposed on the first-order lag evaluations. The degradation in handling qualities from increasing the lag time constant appears similar to the degradation from increasing time delay. Various degrees of PIO occurred in each of the inadequate (level 3) cases. The character of the amplitude and frequency of the PIO tended to be similar to that of the \pm 20 $\mathrm{deg} / \mathrm{sec}$ rate limit evaluations. 


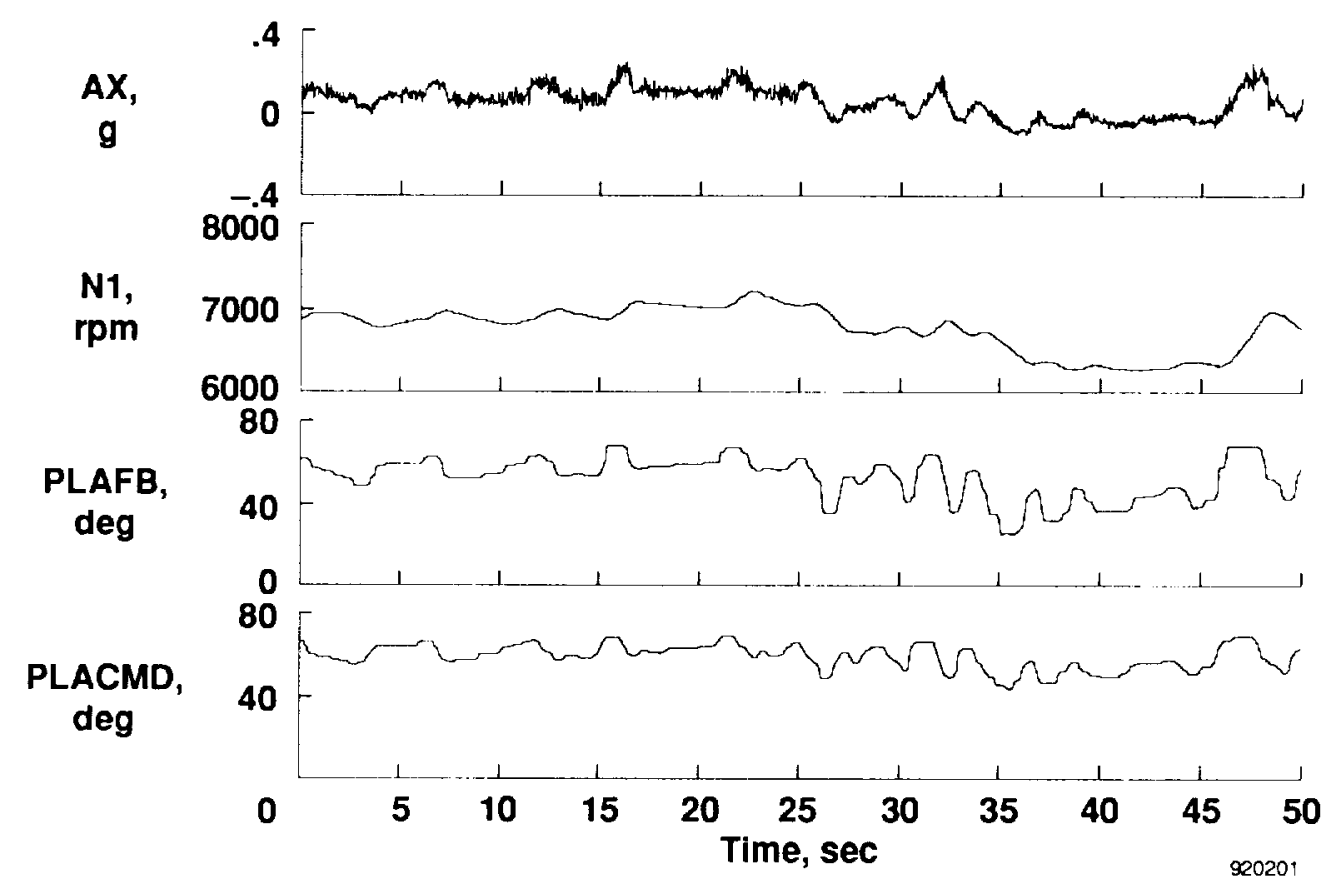

(c) Time histories of pilot $\mathrm{D}, \mathrm{HQR}=6.0$.

Pilot HQR

A $\quad 4.0$

C $\quad 5.5$

\section{Comments}

The throttle feels like the gearing is reduced. More throttle motion is needed for a given thrust change. Took some compensation to get enough thrust to move fore and aft. An HQR of 4 was given based on moderate pilot compensation to get desired performance.

I'm falling into the typical trap of trying to figure out what's going on and have no idea, so I'll admit it. The confusing thing was that there were periods where I had pretty decent performance and then some periods of overcontrol that left me less than happy with the predictability of the basic airplane. So the performance overall was adequate with a reasonable amount of throttle motion. With the initial response, it felt like I was overcontrolling it. At times, I was getting it moving when I wanted it, but generally the final response was not as predictable as I would like. The airplane was controllable with adequate performance.

D $\quad 6.0 \quad$ A little bit of trouble anticipating how much power to take off and when to put it back on as the lead aircraft made changes. The throttle had more motion than I would have liked. Initial and final thrust responses were O.K. I might have been overdriving the throttle a little bit to get the amount of thrust that I wanted out of it in both directions. Controllability was not in question, had adequate performance. Steady state station keeping was no problem. An HQR of 6 was given based on pilot workload. [This pilot initially rated this point as a 5 , then changed it to 6 .]

Fig. 13. Concluded. 


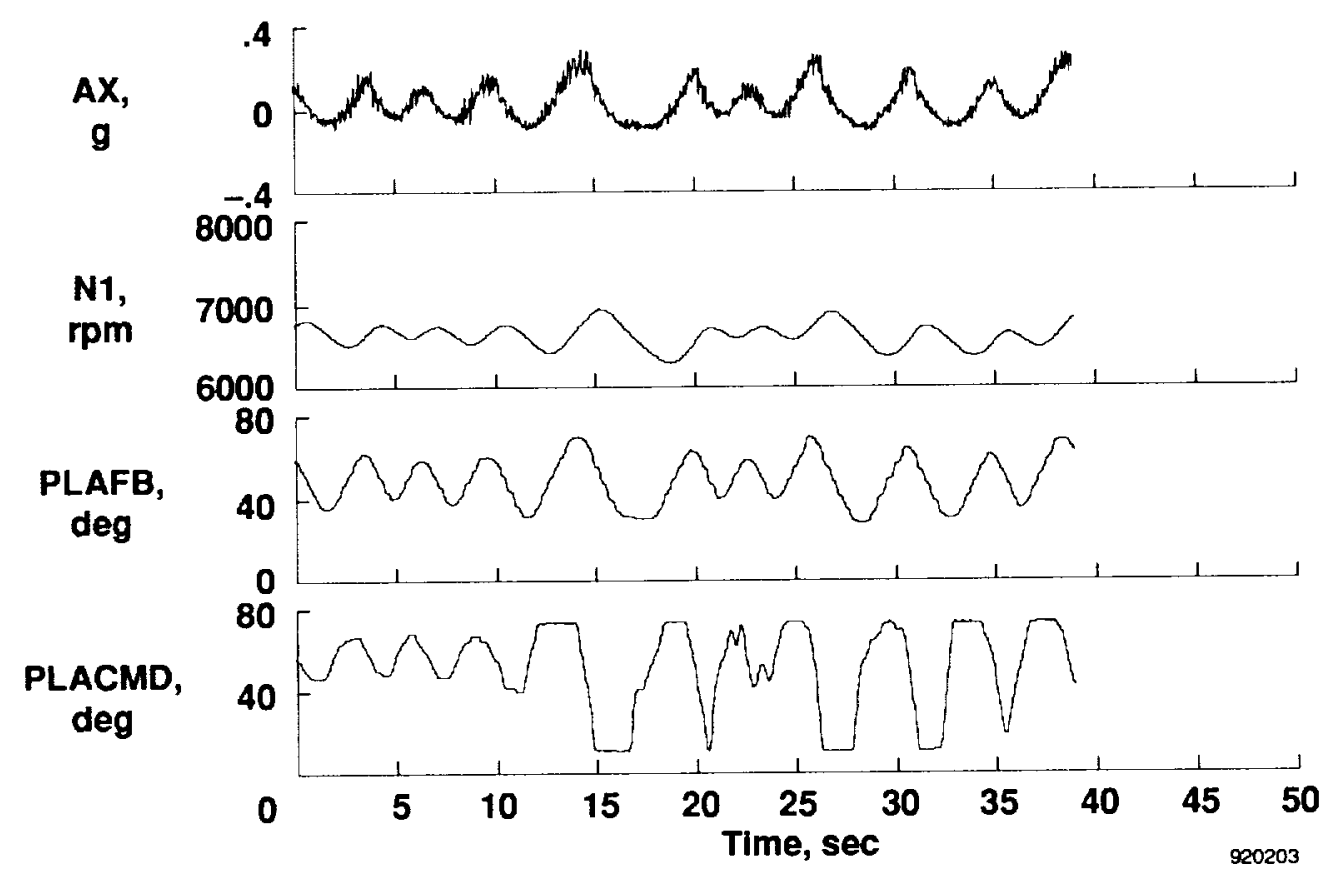

(a) Time histories of pilot $\mathrm{B}, \mathrm{HQR}=10.0$.

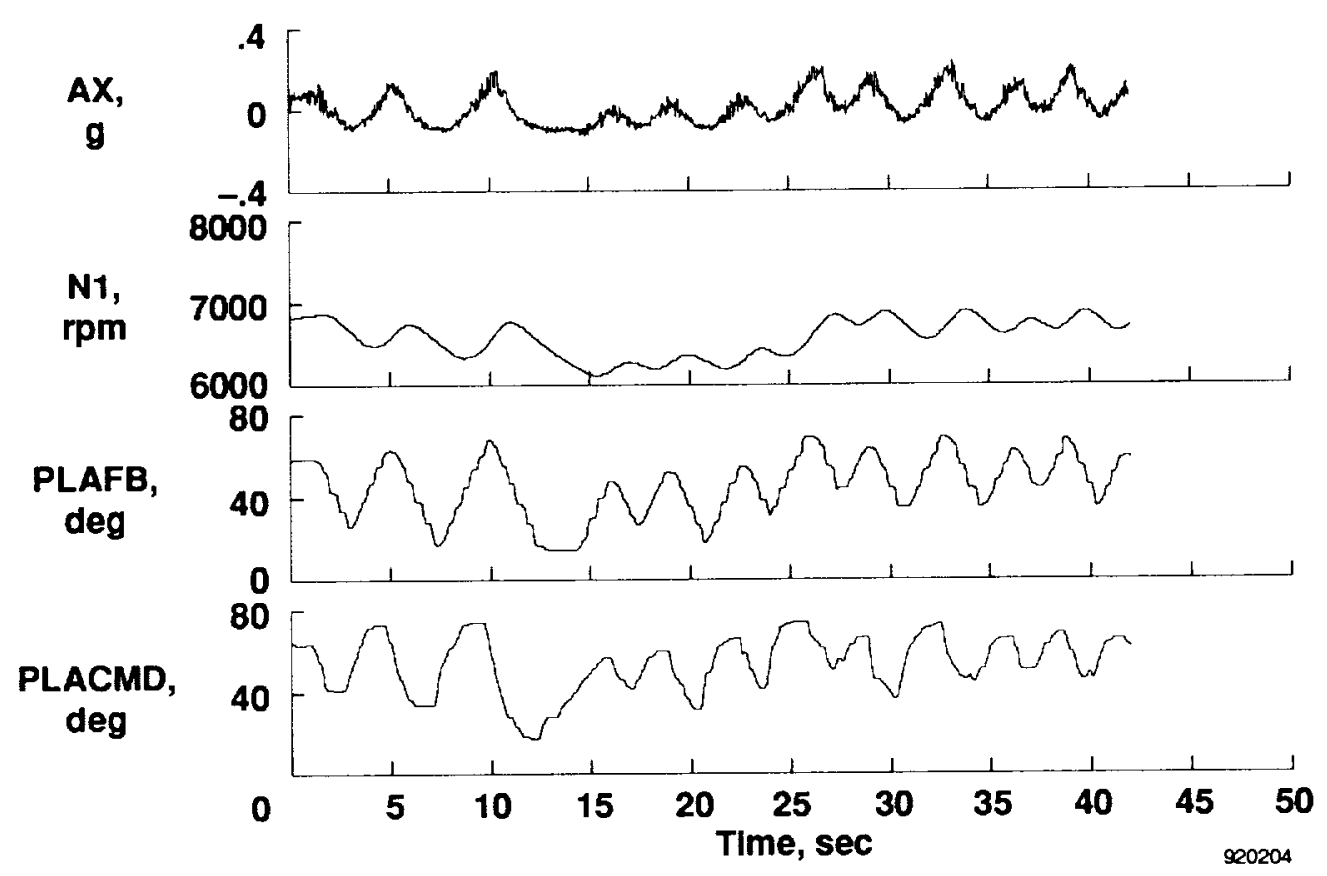

(b) Time histories of pilot $\mathrm{C}, \mathrm{HQR}=9.0$.

Fig. 14. Level 3 handling qualities for rate limit $=20 \mathrm{deg} / \mathrm{sec}$ and time delay $=65 \mathrm{msec}$. 


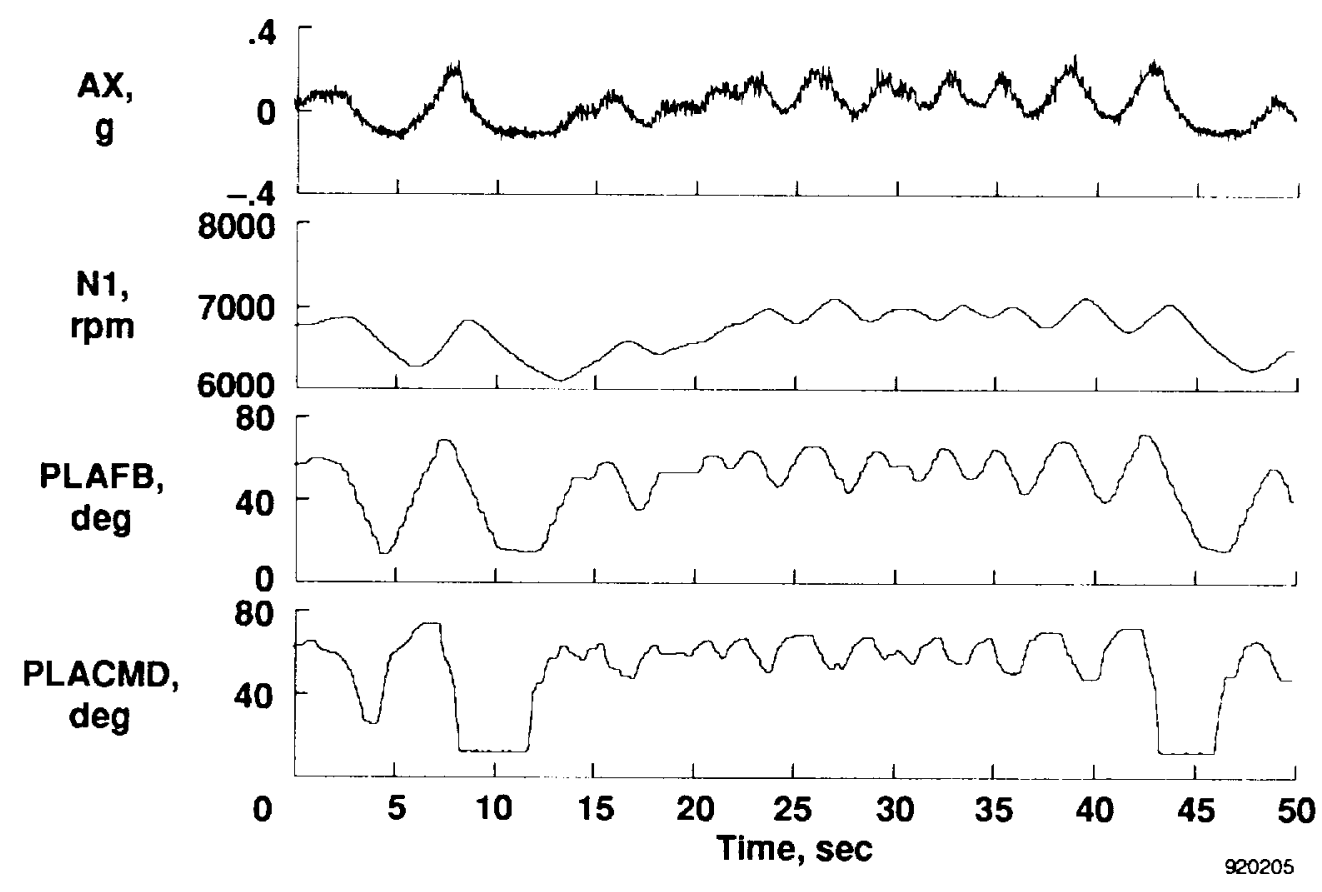

(c) Time histories of pilot $\mathrm{D}, \mathrm{HQR}=9.0$.

Pilot HQR

B $\quad 10.0$

Even for the steady state station keeping I'm making pretty big inputs and lots of motion and not getting the response I expected. There was a PIO tendency. With the lead aircraft changing thrust, I'm just stop-to-stop with the throttle. I have to give that an HQR of 10 . If you were on a boom, you'd be off it pretty quick. You'd have a hard time staying with the guy in any formation flying.

C $\quad 9.0$

The boomer's eyes are very big! Station keeping was really no problem without the throttle jinks. But it seemed like there was $1 / 2$ in. to $3 / 4$ in. of absolute deadband in the throttle. So, I could not achieve desired performance, not even close. And, I think I could hurt somebody. So we're talking 8,9 , or 10 again. It's not clear that I'd have to abandon the task, but it's very close to that.

$\mathrm{D} \quad 9.0$

I had a lot of throttle motion anytime I wanted to do something. The initial thrust response was pretty slow. It appeared to be some sort of a time delay or something that exhibited time delay type characteristics. In the final response, I was never able to nail down where I wanted to leave the throttle. There were no PIO tendencies because I never seemed to get in any one place at any one time. The only PIO was me moving the throttle with no apparent effects. The chase pilot and I had a little discussion about whether that one would have damaged the tanker, and there's no question that it would have.

920206

Fig. 14. Concluded. 


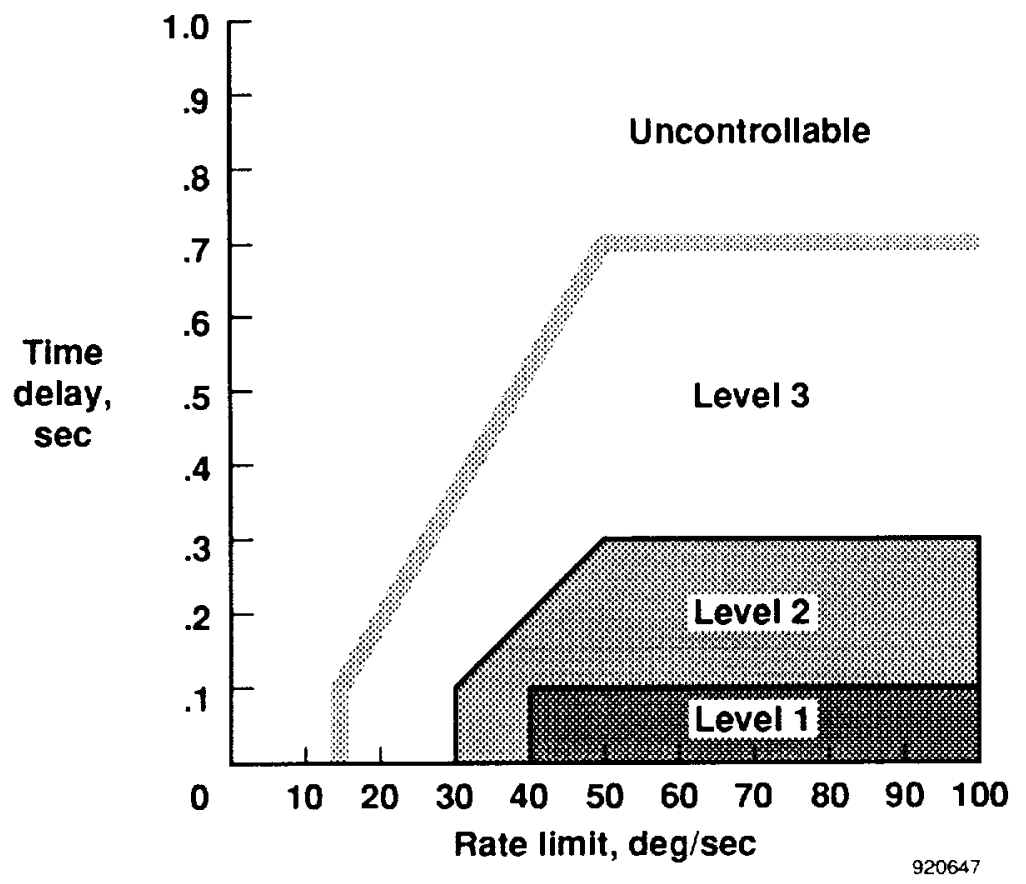

Fig. 15. Level 1,2, and 3 engine handling quality boundaries for time delay and rate limit.

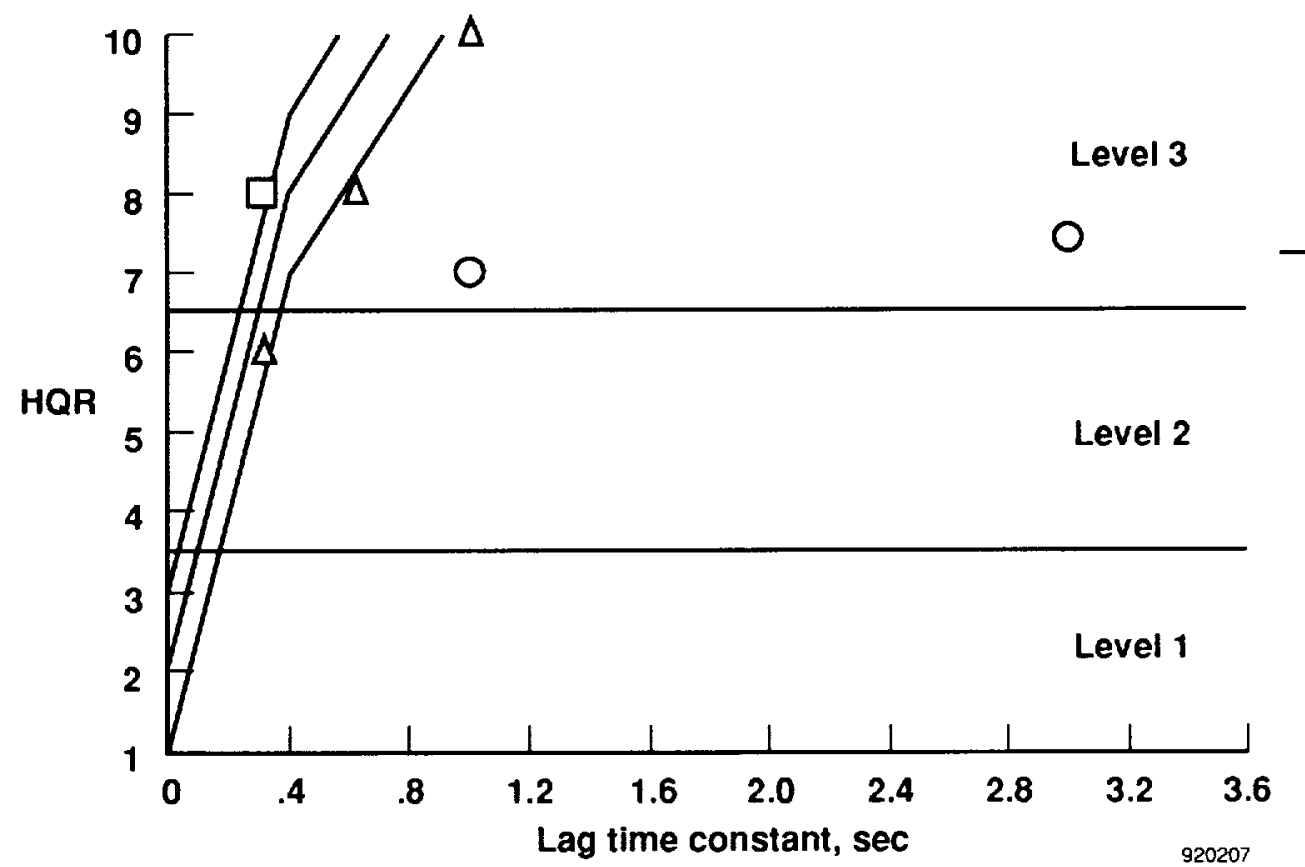

Fig. 16. Effect of first-order lag filter on pilot rating for throttle time delay $=65 \mathrm{msec}$, command gain $=1.5$, and rate limit $= \pm 99 \mathrm{deg} / \mathrm{sec}$. 
Figure 17 shows time history data and pilot $\mathrm{C}$ comments for a lag time constant of $0.3 \mathrm{sec}$. This time constant represents the only adequate (level 2) handling qualities data point. The effects of the first-order lag filter are similar in throttle motion and magnitude to the pure time delay effects (Fig. 10(a)). Pilot C commented that station keeping was not too bad, but it got worse when attempting to match throttle changes by the lead airplane. This pilot said that the throttle felt as though he/she were PIO'ing the throttle. Extensive pilot compensation was required; therefore, an HQR of 6.0 was given.

Figure 18 shows two sets of time histories of inadequate (level 3 ) handling qualities and pilot $\mathrm{C}$ comments. Comparing Figs. 17 and 18 shows the effect of increasing the lag time constant from 0.3 through 0.6 to $1.0 \mathrm{sec}$. Increasing the lag time constant significantly increased the throttle motion by the pilot. The pilot noted PIO and much throttle input for the $0.6-$ and 1.0-sec lag time constant configurations. Observe that the frequency decreased from approximately
0.25 to $0.20 \mathrm{cycles} / \mathrm{sec}$. The pilot could not control the engine response and was from stop to stop with the throttle (Fig. 18(b)) for the 1.0-sec case. As a result, an HQR of 10.0 was given.

Figure 19 shows two sets of time histories and pilot comments for lag time constants of 1.0 and $3.0 \mathrm{sec}$ which describe inadequate (level 3) handling qualities for pilot $A$. Note the similarity between the throttle motions of pilots A (Fig. 19(a)) and C (Fig. 18(b)) for a 1.0-sec lag time constant. Figure 19(a) also shows that pilot A moved the throttle from stop to stop. Pilot comments were also similar. Pilot $A$ noted large thrust delays and overshoots in both directions and was unable to obtain adequate performance. Sote that pilot A rated this configuration a 7.0 compared to a 10.0 for pilot C. Figure 19(b) shows a 3.0-sec lag time constant time history for pilot $A$. The frequency of throttle motion decreased significantly from 0.2 to between 0.1 and 0.05 cycles $/ \mathrm{sec}$. Pilot $A$ commented that the rate was so slow that it was impossible to stabilize the airplane in formation and rated this configuration a $7 . \bar{i}$.

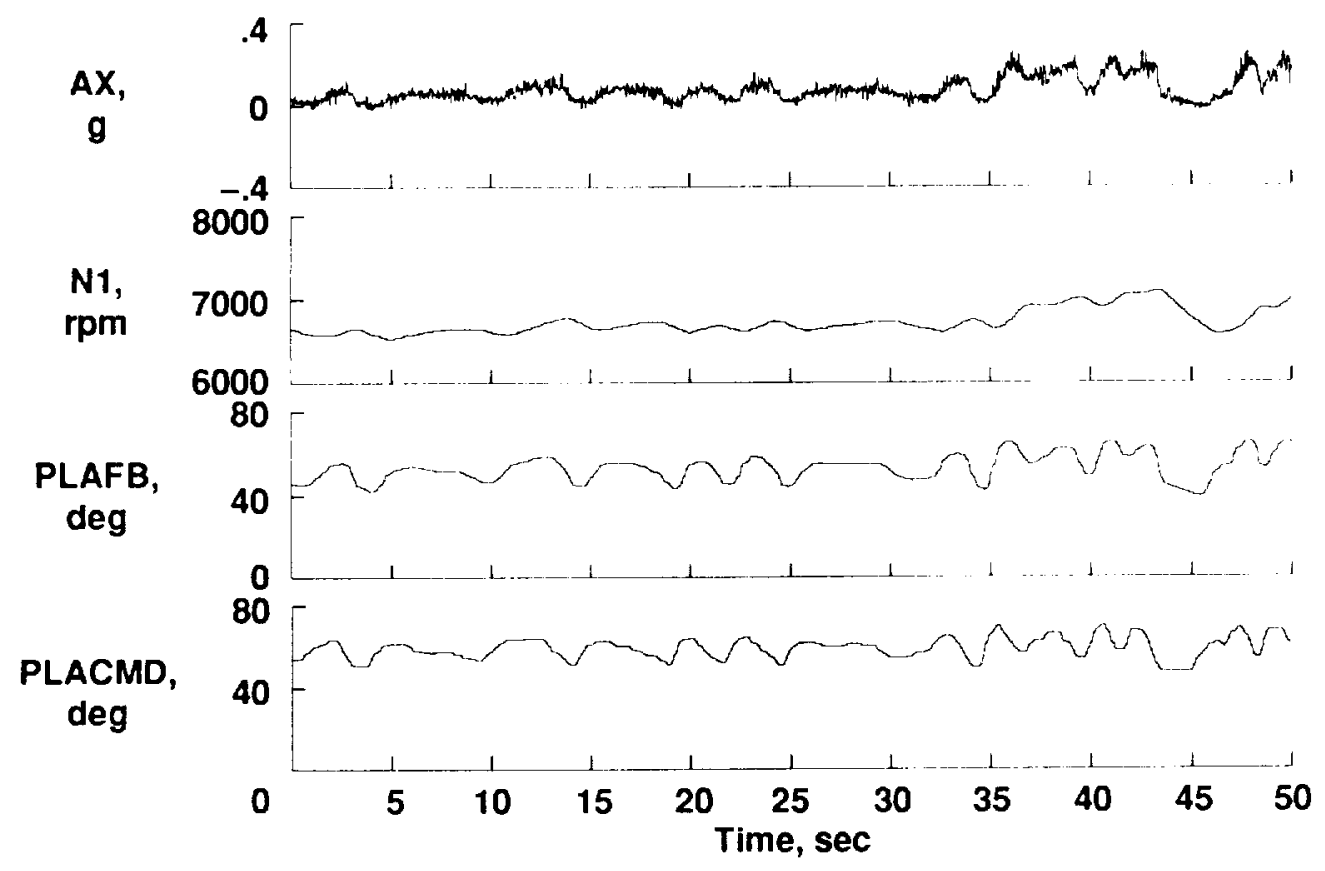

Station kecping isn't too terribly bad, but I'm putting in an awful lot of inputs in the throttle, and pretty big inputs too. I'm slowly going forward and aft with the throttle. I'm not secing a classic PIO, but I am PIO'ing the throttle. Things get worse when trying to match throttle changes of the lead aircraft. Deficiencies certainly warrant improvement. Extensive pilot compensation is required. An HQR of 6 was given.

Fig. 17. Time histories and pilot $\mathrm{C}$ comments describing level 2 handling qualities for lag time constant $=0.3 \mathrm{sec}$, command gain $=1.5$, time delay $=65 \mathrm{msec}$, and rate limit $= \pm 99 \mathrm{deg} / \mathrm{sec}$. 


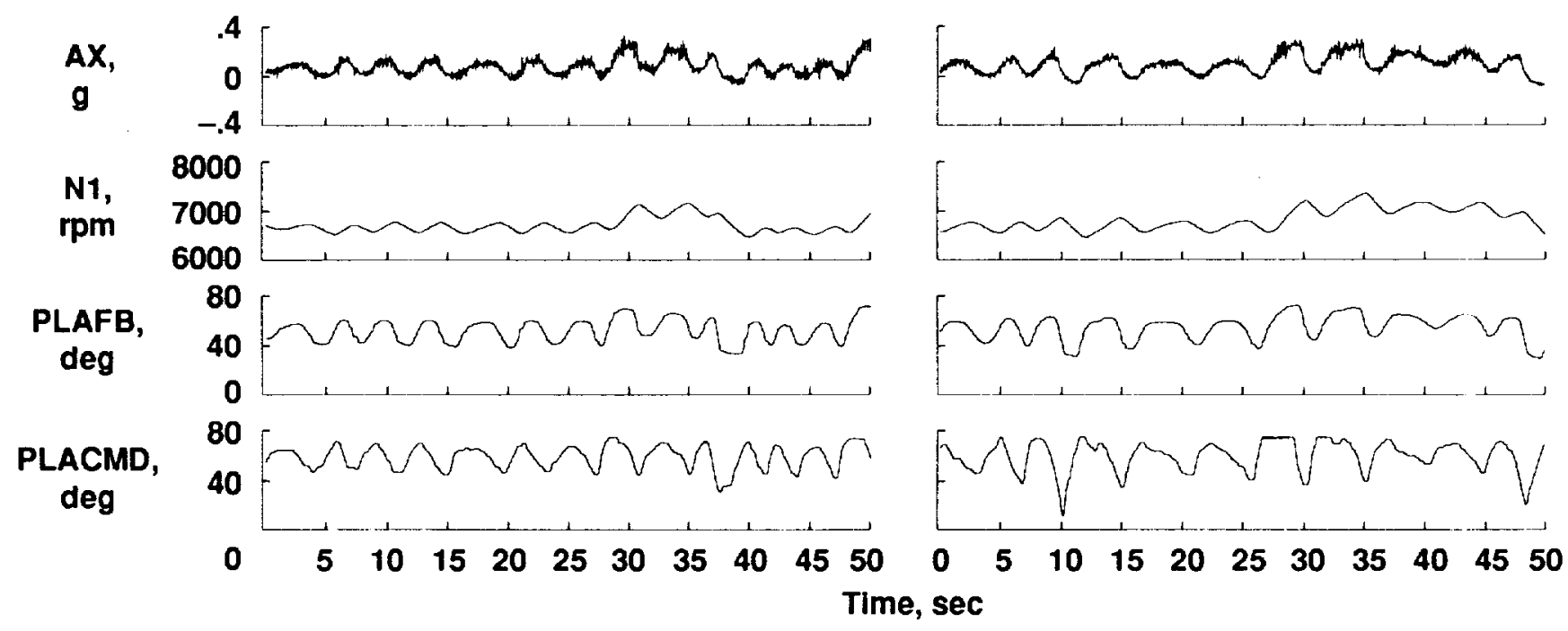

(a) Lag time constant $=0.6 \mathrm{sec}, \mathrm{HQR}=8.0$.

(b) Lag time constant $=1.0 \mathrm{sec}, \mathrm{HQR}=10.0$.

\begin{tabular}{|c|c|c|}
\hline $\begin{array}{l}\text { Lag time } \\
\text { constant, } \\
\text { sec }\end{array}$ & HQR & Comments \\
\hline 0.6 & 8.0 & $\begin{array}{l}\text { I don't know what the problem is. But every time I get in a stabilized station } \\
\text { keeping position, I see some acceleration or deceleration. It just falls apart on } \\
\text { me. It definitely needs improvement when trying to track throttle changes of } \\
\text { the lead aircraft. I was really oscillating and PIO'ing and lots of throttle input. } \\
\text { I consider this to be a major deficiency; therefore, and HQR of } 8 \text { is given. }\end{array}$ \\
\hline 1.0 & 10.0 & $\begin{array}{l}\text { I really can't control it. I'm about } 50 \mathrm{ft} \text { away and almost stop-to-stop with the } \\
\text { throttle now. I'm really trying to slow my gain down in manipulating the throttle } \\
\text { but I'm still seeing a PIO. I have to give that a } 10 \text {. I don't think that if I'd been } \\
\text { out over the Atlantic, and I needed fuel, I'd have been able to do that safely. } \\
\text { I'm just seeing the throttle go stop-to-stop and that's completely unsatisfactory. }\end{array}$ \\
\hline
\end{tabular}

920209

Fig. 18. Time histories and pilot $\mathrm{C}$ comments describing the effects of increasing lag time constants for level 3 handling qualities for command gain $=1.5$, time delay $=65 \mathrm{msec}$, and rate limit $= \pm 99 \mathrm{deg} / \mathrm{sec}$.

\section{Lead-Lag Filter Effect}

Handling quality evaluations were conducted to study the effects of appropriate first-order lead-lag filters in combination with additional time delay. This study was to determine if suitable lead compensation could offset the handling qualities degradation of throttle system time delay.

Figure 20 shows the data obtained using the lead-lag filter to compensate for additional time delay. Configurations with 165 - and $265-\mathrm{msec}$ time delay were evaluated. Superimposed on this figure is the $\pm 1 \mathrm{HQR}$ band from Fig. 8. Unfortunately, the database for this experiment was insufficient for use in drawing conclusions. The data remained within the \pm 1 HQR band. The HQR trends suggested some improvement with the lead compensation for the 165-msec cases, but the few evaluations flown showed inconsistencies between some HQR's and pilot comments. The overall ratings remained essentially unchanged with the added lead compensation filters for the larger 265 -msec cases. 


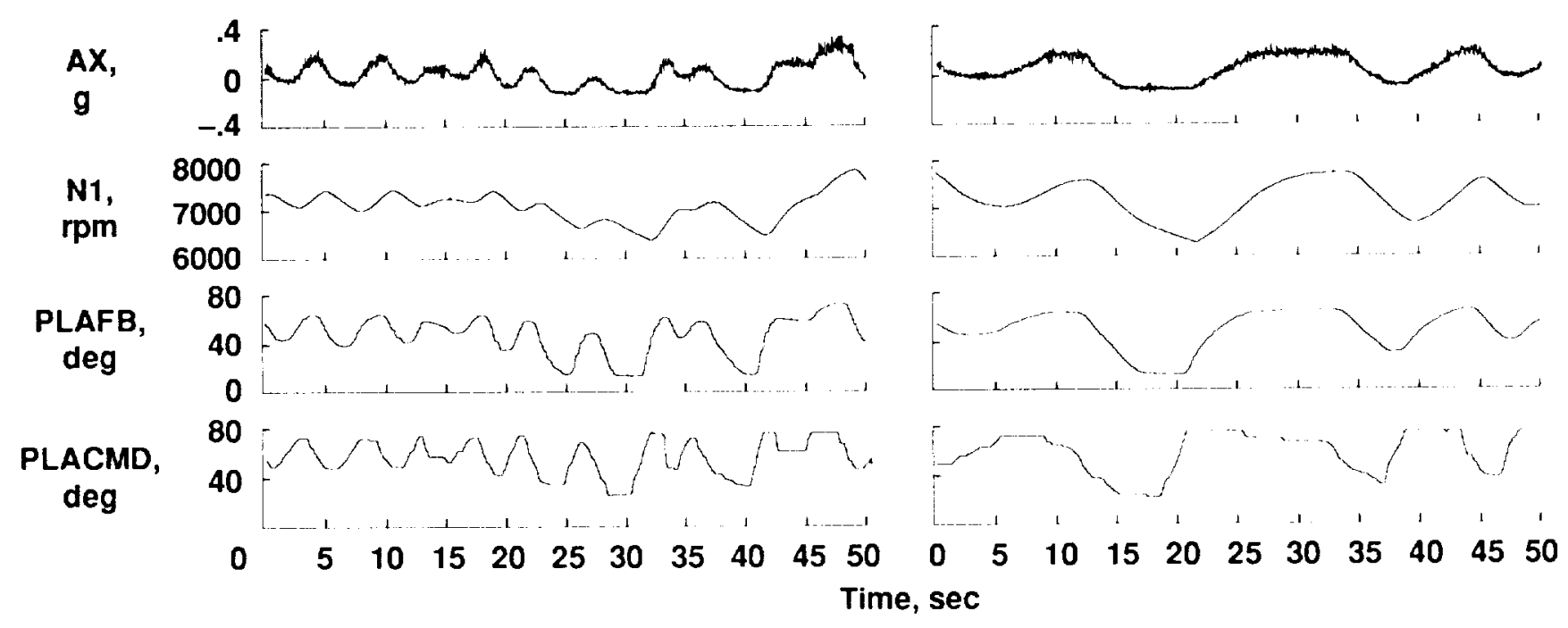

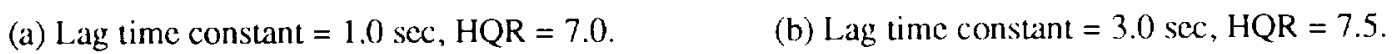

$\begin{aligned} & \text { Lag time } \\ & \text { constant, } \\ & \text { sec }\end{aligned}$
1.0
$7.0 \quad$ Comments
3.0
$\begin{aligned} & \text { There was a big delay and big overshoots in both directions. I couldn't do an } \\ & \text { adequate job. Even with all that I could bring to bear on it, I couldn't get aded } \\ & \text { performance. }\end{aligned}$
$\begin{aligned} & \text { I'm not even in formation but get the impression that the rate is very slow. } \\ & \text { Particularly when you add throtle, the rpm doesn't change very fast. I wish } \\ & \text { you could sec this on TV. This is wild. The rpm rate is so slow that it's just } \\ & \text { impossible to stabilize this in formation. }\end{aligned}$

Fig. 19. Time histories and pilot A comments describing the effects of increasing lag time constants for level 3 handling qualities for command gain $=1.5$, time delay $=65 \mathrm{msec}$, and rate limit $= \pm 99 \mathrm{deg} / \mathrm{sec}$. 


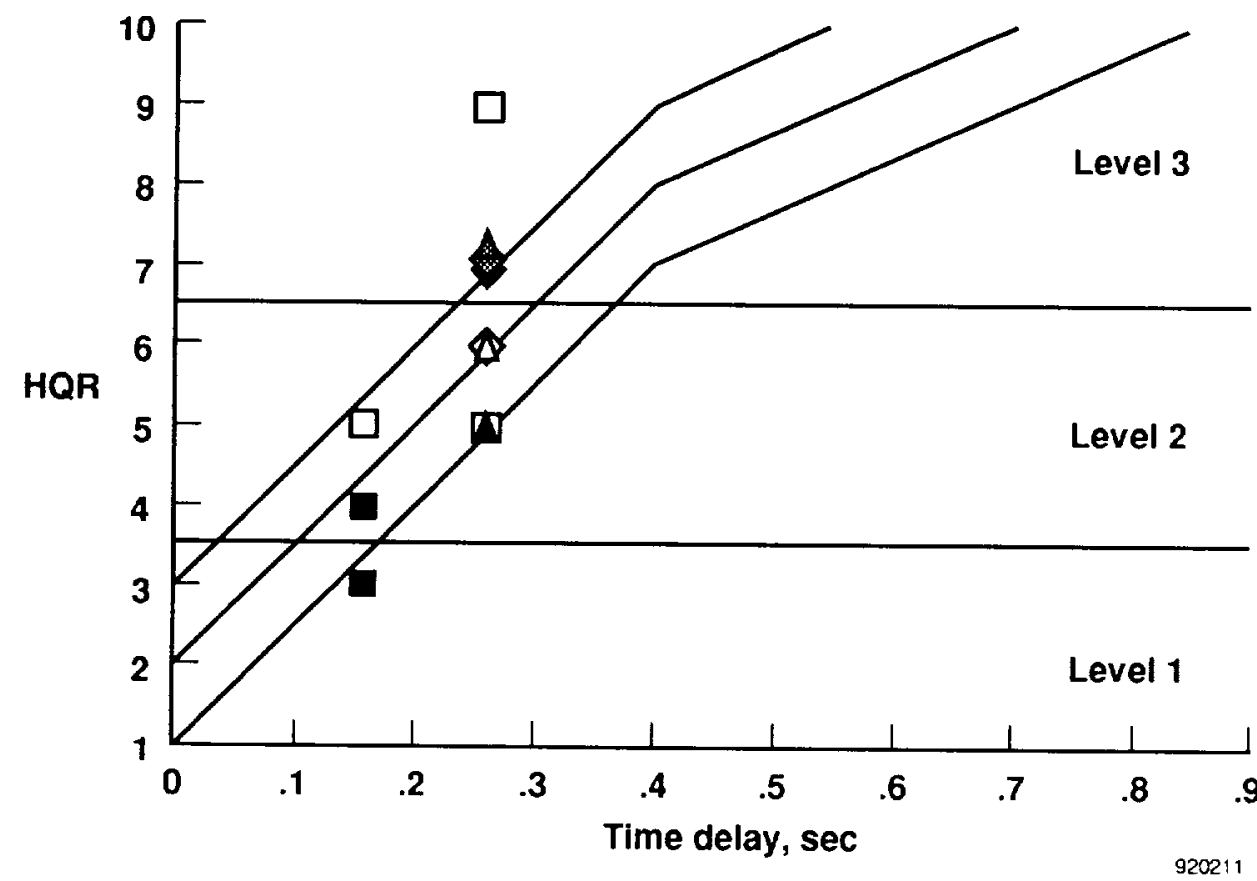

Fig. 20. Effect of lead-lag compensation for additional time delay on pilot ratings for command gain $=1.5$, time delay $=65 \mathrm{msec}$, and rate limit $= \pm 99 \mathrm{deg} / \mathrm{sec}$.

\section{Concluding Remarks}

A flight evaluation was conducted at the Dryden Flight Research Facility to investigate the effects of varying engine throttle response on airplane handling qualities. An electronic throttle control system in a TF-104G airplane was used to evaluate the effects of throttle time delay, rate limit, first-order lag time constant, and lead-lag time constant. The Cooper and Harper Pilot Rating Scale was used to describe satisfactory, adequate, and inadequate (level 1,2, and 3) handling qualities. A precise longitudinal, close-wing station keeping task was flown to simulate such operations as air-to-air refueling and close-formation flight under adverse instrument conditions. The formation leader introduced small and unannounced step throttle changes to challenge the evaluation pilot. These changes provided the desired degree of handling qualities discrimination. Highlights of the result are summarized next.

For level 1 handling qualities, throttle time delay should be less than $100 \mathrm{msec}$; and rate limit should be greater than $40 \mathrm{deg} / \mathrm{sec}$. Thrust pilotinduced oscillations occurred for time delay values greater than $250 \mathrm{msec}$ and rate limits less than 25 $\mathrm{deg} / \mathrm{sec}$. A steep degradation of handling quality rating occurred with added time delay. Decreasing throttle rate limits to $\pm 45 \mathrm{deg} / \mathrm{sec}$ had $\mathrm{min}$ imal effect in changing the engine handling qualities. A sharp degradation in handling qualities occurred with rate limit values less than $\pm 40 \mathrm{deg} / \mathrm{sec}$.
Handling quality ratings at $\pm 40 \mathrm{deg} / \mathrm{sec}$ ranged from 2 to 6 , thereby suggesting initial handling quality degradation.

An insufficient number of lag time constants were evaluated for determining satisfactory (level 1) or adequate (level 2) airplane handling qualities. Except for one test point, the data resulted in inadequate (level 3) handling qualities. When the same \pm 1 handling quality rating band obtained from the time delay evaluations was applied to the lag time constant evaluations, the degradation in handling qualities from increasing the lag time constant appeared similar to the degradation from increasing time delay.

The attempt to identify the effect of adding leadlag time constants with additional time delay to determine if lead compensation could offset handling quality degradations was inconclusive. Data for the lead compensation configuration remained within the \pm 1 rating band of the uncompensated configuration data.

\section{References}

${ }^{1}$ Burcham, Frank W., Jr., Lawrence P. Myers, and John R. Zeller, Flight Evaluation of Modifications to a Digital Electronic Engine Control System in an F-15 Airplane, NASA TM-83088, 1983. (Also available as AIAA-83-0537, Jan. 1983.)

${ }^{2}$ Myers, Lawrence P. and Frank W. Burcham, Jr., Propulsion Control Experience Used in the Highly 
Integrated Digilal Electronic Control (IIIDEC) Program, NASA TM-85914, 1984.

${ }^{3}$ Walker, Laurence A., "Harrier II--Digital Engine Control Flight Tests," 30th Symposium Proccedings, Society of Experimental Test Pilots, Sept. 24-27, 1986, pp. 49-70.

${ }^{4}$ Cooper, George E. and Robert P. Harper, Jr., The Use of Pilot Rating in the Evaluation of Aircraft Handling Qualities, NASA TN D-5153, 1969.
${ }^{5}$ Neal, Bradford and Upal Sengupta, The Implementation and Operation of a Variable-Response Electronic Throttle Control System for a TF-104G Aircraft, NASA TM-101696, 1989.

${ }^{6}$ Hoh, Roger H., "Unifying Concepts for Handling Qualities Criteria," AIAA-88-4328, Aug. 1988.

${ }^{7}$ U.S. Air Force, Military Specification-Flying Qualities of Piloted Airplanes, MIL-F-8785C, Nov. 1980. 




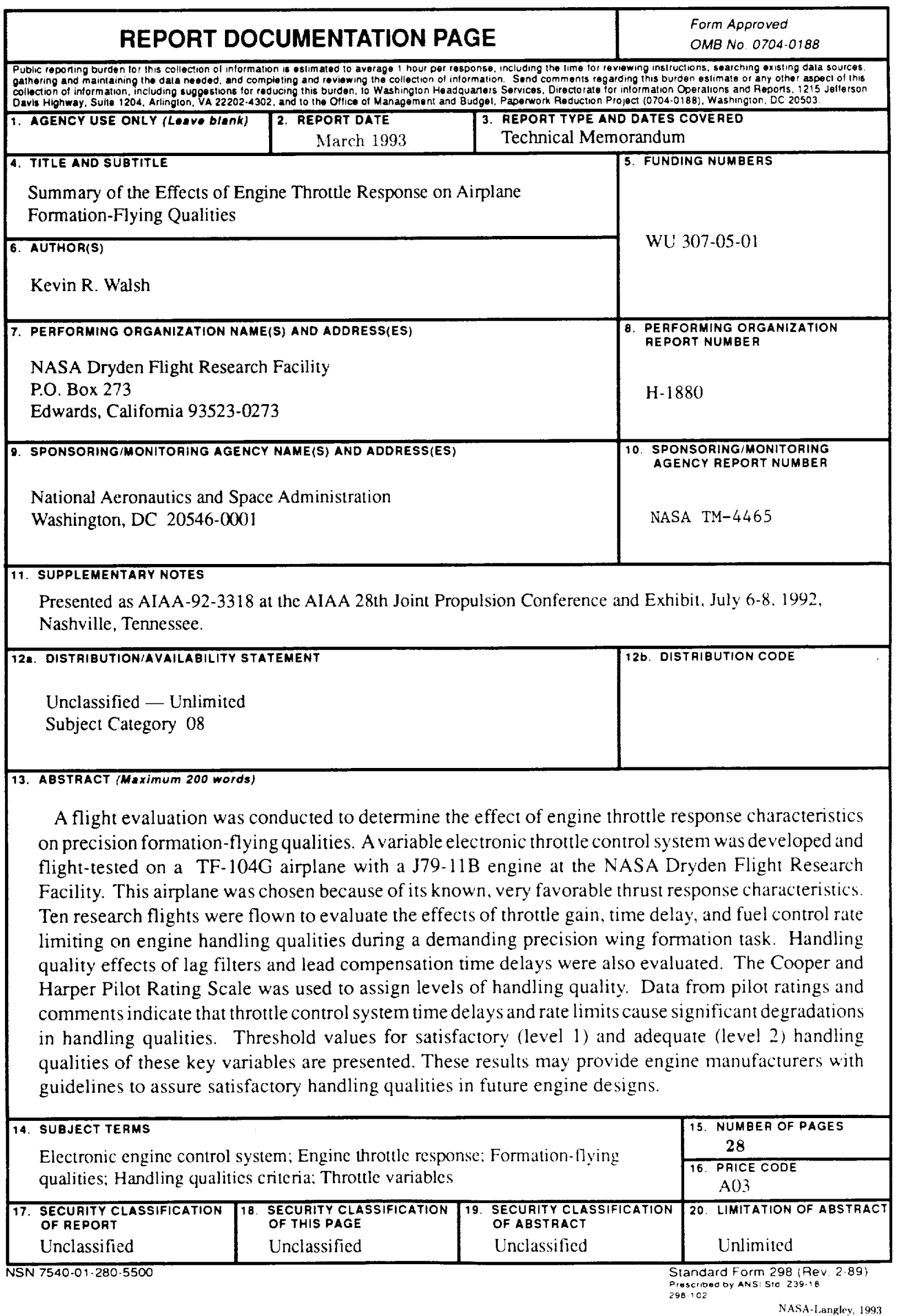

